Discussion Papers of the

Max Planck Institute for

Research on Collective Goods

2020/19

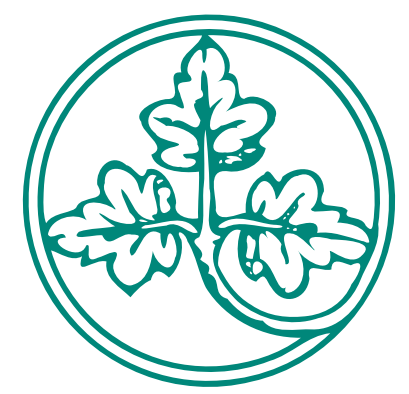

Trustworthiness in the

Financial Industry

Andrej Gill

Matthias Heinz

Heiner Schumacher

Matthias Sutter 


\title{
Trustworthiness in the Financial Industry
}

\author{
Andrej Gill / Matthias Heinz / Heiner Schumacher / Matthias Sutter
}

August 2020 


\title{
Trustworthiness in the Financial Industry*
}

Andrej Gill ${ }^{\S}$, Matthias Heinz ${ }^{\delta}$, Heiner Schumacher ${ }^{\infty}$, and Matthias Sutter ${ }^{\beta}$

\begin{abstract}
The financial industry has been struggling with widespread misconduct and public mistrust. Here we argue that the lack of trust into the financial industry may stem from the selection of subjects with little, if any, trustworthiness into the financial industry. We identify the social preferences of business and economics students, and follow up on their first job placements. We find that during college, students who want to start their career in the financial industry are substantially less trustworthy. Most importantly, actual job placements several years later confirm this association. The job market in the financial industry does not screen out less trustworthy subjects. If anything the opposite seems to be the case: Even among students who are highly motivated to work in finance after graduation, those who actually start their career in finance are significantly less trustworthy than those who work elsewhere.
\end{abstract}

JEL codes: C91, G20, M51

Keywords: Trustworthiness, Financial Industry, Selection, Social Preferences, Experiment

\section{August 2020}

\footnotetext{
* We would like to thank Loukas Balafoutas, Björn Bartling, Alain Cohn, Anna Piil Damm, Thomas Dohmen, Ernst Fehr, Guido Friebel, Andreas Hackethal, Jürgen Huber, Bernd Irlenbusch, Alexander Koch, Michael Kosfeld, John List, Michel Marechal, Devesh Rustagi, Antoinette Schoar, Dirk Sliwka, Matthias Stefan, Uwe Walz, and Achim Wambach, as well as seminar participants at Aarhus University, Copenhagen University, University of Chicago, and the Society for Experimental Finance Annual Meeting for valuable comments. We thank David Heller, Sebastian Koch, Stephan Krehl, Christopher Kroh, Jana Schneider, David Schuch, and Katharina Tilts for excellent research assistance. Financial support from the Deutsche Forschungsgemeinschaft (DFG, German Research Foundation) under Germany's Excellence Strategy - EXC 2126/1- 390838866 and from the Center for Financial Studies (CFS) is gratefully acknowledged.

§ University of Mainz. Email: gill@uni-mainz.de.

${ }^{\delta}$ University of Cologne, ECONtribute, Max Planck Institute for Research on Collective Goods, Bonn, and CEPR. Email: heinz@wiso.uni-koeln.de.

${ }^{\infty}$ KU Leuven, and University of Innsbruck. Email: heiner.schumacher@kuleuven.be.

${ }^{\beta}$ Corresponding author. Max Planck Institute for Research on Collective Goods, Bonn, University of Cologne, ECONtribute, IZA Bonn, CESifo Munich and University of Innsbruck. Phone: +49 228914 16 150; Email: matthias.sutter@coll.mpg.de.
} 


\section{Introduction}

The financial industry serves a crucial role in every modern society. Most importantly, it allows businesses to finance projects and consumers to purchase property and to accumulate wealth for retirement. A well-functioning financial market is therefore of the utmost importance for social welfare. This is also reflected in the financial industry's large share of GDP in modern economies (currently accounting for about $20 \%$ of GDP in the United States, for example). ${ }^{1}$

However, the financial industry struggles with several problems that compromise its benefits for society. Recent studies show widespread misconduct in retail finance (Mullainathan et al. 2012, Egan et al. 2019), asset quality misrepresentation on multiple levels (Piskorski et al. 2015, Griffin and Maturana 2016), and insufficient sanctioning of misconduct (Egan et al. 2019). In fact, the European Central Bank estimates the annual costs of misconduct in the financial industry at about 350 billion US-Dollars (or the equivalent of $15 \%$ of bank equity). ${ }^{2}$ Overall, scholars argue that the many scandals and affairs have substantially reduced trust in the financial industry and the financial market (Guiso et al. 2008, Sapienza and Zingales 2012, Zingales 2015).

In this paper, we argue that the lack of trust into the financial industry stems from the selection of subjects with little, if any, trustworthiness into the financial industry. In order to show this, we identify the degree of trustworthiness of business and economics students several years before they enter the labor market, and follow up on their professional specialization as well as their job placement after graduation. Our long-term project started with a data collection wave in 2013 in which we asked 265 business and economics students at Goethe University Frankfurt, Germany, about their professional preferences and their interest in working in different industries. Frankfurt is an ideal place for such a project because it is an important hub for the financial industry and attracts many students who are interested in working in this industry. In 2013, students also participated in an experimental trust game (Berg et al. 1995) in order to elicit in particular their level of trustworthiness. ${ }^{3}$ Here we use the trust game to study selection into a major industry of the global economy, namely the financial industry. With the data from 2013, we can examine whether there is a relation between trustworthiness and the industry in which students would like to work in the future. Of course, any potential relationship

\footnotetext{
${ }^{1}$ See the United States' Bureau of Economic Analysis: https://www.bea.gov/data/gdp/gdp-industry (accessed 31 July 2020).

${ }^{2}$ See the Financial Stability Report of the European Central Bank (ECB) https://www.ecb.europa.eu/pub/financialstability/fsr/focus/2019/html/ecb.fsrbox201911_03 511ae02cc5.en.html (accessed 31 July 2020).

${ }^{3}$ Behavior in the trust game has been shown to correlate with real-world decisions, in particular with loan repayments (Karlan 2005), charity donations (Baran et al. 2010), and effort provision at the workplace (Cohn et al. 2014b).
} 
could easily be discarded as cheap talk of students about their future career plans. In order to address this valid concern, we ran a second wave of data collection more than six years later, in late 2019 and early 2020. We contacted all subjects who took part in our wave from 2013 and managed to reach $86 \%$ of them, collecting data on actual first job placement after graduation and many more details of their career paths. Following up subjects on their career paths from their college days into their first permanent job is important for three reasons.

First, the labor market in the financial industry is very competitive. If a subject indicates (in 2013) that she is strongly interested to work in the financial industry, this does not automatically imply that she will get a job offer from a financial company. This means that, in addition to knowing who intends to work in the financial industry, the actual job placement reveals whom the financial industry selects and admits. Second, our long-term project allows identifying how a student's interest in working in the financial industry is related to actual job placements after graduation. In other words, we can examine whether what students indicate as their professional interest during college days is only cheap talk or a good predictor of their actual professional career. This is only possible if the demand of the financial industry for employees with particular characteristics actually meets the supply side of students with such characteristics. Third, entering the financial industry after graduation is a decision with longterm consequences. Ellul et al. (2020) show that only a small share of individuals switch from the financial industry to another industry and vice versa. The same is true in our study as less than $4 \%$ of subjects switch from the financial industry to another one or vice versa within an average of three years into the first permanent job. Therefore, it becomes all the more important to understand who selects into the financial industry at the beginning of a career because those who do can be expected to stay for a long time.

Looking first at the data from 2013 only, we find that there is no difference in individuals' trust ${ }^{4}$, but a remarkable difference in trustworthiness, contingent on their professional preferences. We find a significant negative correlation between an individual's desire to work in the financial industry and the degree of trustworthiness: The third of students most interested in working in finance after completing their studies return on average around 30 percent less in the trust game than the third of subjects least eager to work in finance. Importantly, this relationship remains unchanged if we focus on subjects who in 2013 did not

\footnotetext{
${ }^{4}$ Note that we are not primarily interested in whether individuals who might end up in the financial industry trust other subjects, but whether they are trustworthy (for potential future customers and co-workers), for which reason we consider our measure of trustworthiness to be the prime outcome to look at.
} 
have any professional experience in the financial industry, and therefore have not been exposed to the business culture there yet.

Of course, such a negative relationship between interest in the financial industry and one's trustworthiness would not be of any concern to the financial industry (and society in general) if the financial industry screened out the less trustworthy candidates in their hiring procedures. Yet, we demonstrate with our data from 2020 that the job market does not alleviate the selection of less trustworthy individuals into finance. Subjects who find their first job after graduation in the financial industry returned in 2013 on average around 30 percent less than subjects who start their career in another industry. Strikingly, even when we focus on the third of students who are most eager to work in finance, we find a behavioral difference between students whose first job placement is in the financial industry and those who find a job elsewhere: The former group returns on average 50 percent less than the latter group. This suggests that the job market does not reduce the selection of less trustworthy individuals into the financial industry; if anything, the opposite seems to be the case.

By examining the career paths of our participants (including, e.g., their study specialization, internships, vocational training or applications after graduation), we can show that subjects who get their first permanent job in the financial industry do not accidentally get into this industry. Rather, their expression of interest in this industry strongly correlates with their professional activities and specialization and thus paves the way to get a job in the financial industry. This implies that there is a strong correlation between a subject's stated interest to work in the financial industry and the actual first job placement after graduation. In other words, the selection of less untrustworthy subjects into the financial industry looks like a systematic pattern.

Such a selection is problematic since many transactions in financial markets are characterized by asymmetric information (often created by the complexity of financial contracts) and a conflict of interest between expert sellers and consumers. Even though there are substantial legal protections of consumers' interests, monitoring is typically very costly and often practically impossible, for which reason clients have to trust their financial experts to make recommendations or perform actions that are beneficial (or at least not detrimental) to them (Gambretta 2000, Sapienza and Zingales 2012, Gennaioli et al. 2015). However, previous research has documented a substantial heterogeneity in the willingness of better-informed parties to cheat on less informed ones who therefore need to trust the former (Gneezy 2005, Balafoutas et al. 2013, Huck et al. 2016). Given our finding that individuals who are hardly trustworthy and may thus exploit situations of asymmetric information have a desire to work in 
the financial industry and are actually admitted by this industry, this helps to understand the sources of misconduct in this industry and why the public lacks trust in it.

Our paper contributes to three strands of literature. First, it contributes to the literature on human capital and selection into the financial industry. Philippon and Reshef (2012) study the allocation of talent in the financial industry. They demonstrate that since the $1980 \mathrm{~s}$ the financial industry turned into a high-skill and high-wage industry, and that a reduction in regulation increased the demand for skilled labor (see also Boustanifar et al. 2018 or Célérier and Vallée 2019). Adams at al. (2016) compare the family values of investment professionals and workers outside finance. They find that relatively few women become investment professionals. Importantly, those women are less tradition- and conformity-oriented and more achievement-oriented than women outside finance and male investment professionals. Ellul et al. (2020) analyze the employment history of a random sample of workers to study patterns of careers in finance. They find that 80 percent of workers who start a career in finance still work in this industry 10 years later. In non-finance sectors, the retention rate is equally high. An important reason for this is that entering a certain industry requires building up industry-specific skills. The specialization choices of the young professionals in our sample therefore are likely to have long-lasting effects on their future employment and the industry in which they will be working. We contribute to this literature by documenting selection into the financial industry based on trustworthiness as an important social preference.

Second, our paper is related to a growing literature that analyzes the extent to which individuals self-select into the non-profit or public sector based on social preferences. Gregg et al. (2011) find in British household panel data a positive correlation between self-selection into the non-profit sector and propensity to work unpaid overtime. Serra et al. (2011) report for Ethiopia that pro-socially motivated health care workers are more likely to work in the nonprofit sector where they earn lower wages. Three recent papers study selection based on social preferences into the public sector. Hanna and Wang (2017) show that students in India who cheat in a laboratory task are more eager to work in the public sector. Barfort et al. (2019) find the opposite result for Denmark; students who cheat less in the laboratory report a stronger interest to work in the public sector after graduation. Considering the opposite results of both papers suggests that selection into public service depends significantly on the institutional context that interacts with students' honesty in the lab. It is important to note, however, that both studies do not follow up on their subjects' job placement after graduation so they cannot identify how strong the actual selection into public service is based on honesty or social preferences. Friebel et al. (2019) compare behavior in a trust game of police applicants (when 
they submit their application) and a sample of high school students in a similar age cohort. They find that the former group is more trusting and trustworthy than the latter group. Compared to the papers mentioned here, our paper is the first that (i) identifies selection into occupations based on social preferences by following subjects' careers before and after their first job market placement, which allows us to match intentions and actual outcomes on the job market, and (ii) that focuses on one of the most important industries of the private sector, i.e., the financial industry, thus answering the question whom the financial industry admits as employee.

Third, our paper is most closely related to a recent discussion about the effects of business culture on honesty in the financial industry. In the seminal paper of Cohn et al. (2014a), they find that putting finance professionals (with more than 10 years of tenure in the industry) into the mindset of their daily business makes them significantly more dishonest in an experimental cheating game than when priming them on their private identity (see also the comment by Villeval 2014). While subsequent research has found mixed results (Rahwan et al. 2019; Cohn et al. 2019), this line of research has drawn the community's attention to the role of identities and business culture. Here we argue that the business culture in an industry is shaped by the people who voluntarily decide to work in that industry, which raises the hitherto largely neglected question who selects into the financial industry. For this purpose, it is important to identify subjects' social preferences even before they get any exposure to the financial industry to see whether different types with respect to social preferences, and in particular trustworthiness, sort into the financial industry. One of the main assets of our longterm project is that we follow business and economics students from their early semesters at college until they have spent the first years in a permanent job after graduation, collecting detailed data on early career experience. So, we take an orthogonal approach compared to the literature studying the influence of business culture on honesty in the financial industry and look into the selection of students into the financial industry.

The remainder of the paper is organized as follows. In Section 2, we explain the study design of our long-term project. In Section 3, we present the results. In Section 4, we conduct a number of robustness checks. Section 5 provides further support for selection on social preferences into the financial industry by presenting additional evidence from a public goods game and how students' interest in the financial industry relates to their level of cooperation. Section 6 concludes and discusses the implications of our results. 


\section{Project Design}

Our project consists of two waves of data collection, the first one in 2013, and the second one in late 2019 and early 2020. For convenience, we will refer to both as Wave 2013 and Wave 2020. We describe Wave 2013 in Subsection 2.1, and Wave 2020 in Subsection 2.2. In Subsection 2.3, we explain how we linked the data from both waves. In Subsection 2.4, we discuss how we classified subjects' professional preferences and job placements after graduation.

\subsection{Professional Preferences and Trustworthiness - Wave 2013}

We conducted the first wave of data collection in 2013 at Goethe University Frankfurt, which is the ideal place for two reasons. First, the university offers a study program in business and economics that allows for a strong focus on finance after the first three semesters. Around 40 percent of business and economics students at Goethe University Frankfurt (and of the subjects in our sample) choose their specialization in finance. Second, Frankfurt is the financial center of Germany and continental Europe, which makes it comparatively easy for students at Goethe University to acquire professional experiences in finance before graduation, and to find a job in the financial industry after graduation. According to alumni data, around 30 percent of Goethe University's business and economics graduates find their first job in the financial industry. This number is roughly the same in our sample.

Wave 2013 was run as a laboratory experiment. In the invitation email for the experiment, we asked subjects to bring a current version of their résumé to the lab for an experimental game and a survey on "Study Motivation, Specialization, and Occupational Choice." The experimenter collected the résumés and deleted any personal information (name, address, etc.) in front of the subject before the start of the experiment. Subjects received a showup fee of 20 Euros. The experiment started with a survey on professional preferences. Among other things, subjects answered the following question on a Likert-scale from 1 ("certainly not") to 7 ("definitively"): "To what extent can you imagine working in the following industries in the future?" Besides finance, these industries were health, tourism, logistics, IT/communication, engineering, electronics, car manufacturing, insurance, energy, retail, public service, consulting, and auditing. We chose the industries where most graduates find their first job (based on alumni data from Goethe University Frankfurt). In the survey, we also collected demographic information, the willingness to take risks (as measured by Dohmen et al. 2011), patience (Vischer et al. 2013), and work values (Ronen 1994). After conducting the 
survey, we measured subjects' cognitive ability by using the 12-minute version of Raven's Advanced Progressive Matrices (Bors and Stokes 1998).

Subjects then played an experimental trust game (Berg et al. 1995; see our instructions in the Online Appendix). This game has two player roles, a first mover and a second mover. The first mover is initially given 8 Euros and can send any integer value between 0 and 8 Euros to the second mover. Before reaching the second mover, the amount is tripled. The second mover can then send back any integer value between zero and the tripled amount. We applied the strategy method (Brandts and Charness 2011) so that for each subject we know the behavior as first mover and as second mover for any possible amount received. At the end of the experiment it was randomly determined for which role and which decision a subject was paid.

The behavior as first mover provides a measure for a subject's trust in the opponent. Note, however, that we are not primarily interested in whether subjects trust others, but whether they are trustworthy (for their future co-workers and customers). For this reason, we will focus on a subject's behavior as second mover, which measures the degree of trustworthiness. To quantify the latter, we calculate for each subject the "mean share returned", i.e., the share of the tripled amount that the second mover sends back, on average, to the first mover, aggregated for all possible amounts received.

The experiment was programmed using z-Tree (Fischbacher 2007), and we used ORSEE (Greiner 2015) to recruit subjects. All participants of the lab experiment were students from the business and economics department of Goethe University Frankfurt. Payments were made right after the end of the session. Each session lasted about 60 minutes (including time needed for instructions and payments). On average, subjects earned 26.61 Euros (including the show-up fee).

\subsection{Job Market Placement and Early Career History - Wave 2020}

In late 2019 and early 2020, we contacted all subjects who had participated in Wave 2013 via email (or, if possible, via phone) and invited them to participate in a short telephone interview. We offered all subjects 40 Euros for their participation. The interviews proceeded in two steps.

In the first step, the "interview invitation", we called the subjects and explicitly explained (i) the purpose of the research project ("studying selection into different industries based on personal characteristics", without any reference to the financial industry), (ii) that the answers to our interview questions will be linked to the data from the experiment conducted at Goethe University Frankfurt in 2013, and (iii) that the actual interview would be conducted by research assistants. We assured subjects that they will remain completely anonymous to the 
researchers and that no person will be able to link their identity to choices made in 2013. Subjects then had to declare their consent that we can interview them and merge the data from this interview with the data from Wave 2013.

In the second step, the actual interviews were conducted by our research assistants. In the phone interviews, subjects were asked to describe their professional experiences. Instead of describing them in detail, they could also give us permission to collect the respective data from the job networking sites "LinkedIn" and "Xing" (which are frequently used by young professionals in Germany). Moreover, they were asked how many times they had applied after graduation for jobs in consulting, audit and financial companies. The detailed guides for the interviews can be found in the Online Appendix. ${ }^{5}$

\subsection{Linking Wave 2013 and Wave 2020: Privacy and Attrition}

In Wave 2013, we have asked 265 business and economics students about their professional preferences several years before they enter the labor market and we have played an experimental trust game with them to measure trust and trustworthiness. ${ }^{6}$ In Wave 2020, we have collected details about the same subjects' professional specialization before graduation (study specialization, pre-graduation job experience through internships or student jobs, applications for permanent jobs), as well as the actual job placements after graduation. Matching the data from both waves provides the unique opportunity to examine whether there is an association between trust and trustworthiness and the industry in which students would like to work in the future, and to study whether this association materializes in actual job placements.

When we collected and linked the data from both waves, two important issues had to be taken into account. First, subjects' privacy must not be compromised. To ensure that subjects' anonymity was preserved at all stages of our research project, we set up an elaborate privacy protection process with several "Chinese walls" between different datasets that were handled by different researchers and research assistants. The detailed process is described in Online Appendix II (It was approved by the ethics committee at the University of Cologne and followed the European data protection rules). ${ }^{7}$

\footnotetext{
${ }^{5}$ We registered Wave 2020 on as-predicted.com, while when running Wave 2013 it was still very uncommon to pre-register experiments.

${ }^{6}$ In total, 267 subjects participated in Wave 2013. However, one subject was registered twice in ORSEE and participated twice in the lab experiment. We dropped this subject from our sample.

${ }^{7}$ In a nutshell, a subject's CV is the key to match the data from Wave 2013 and those from Wave 2020. Despite both CVs (from Wave 2013 and Wave 2020) were anonymized, the details about education and work experience allow for an unambiguous matching, while at the same time keeping them anonymous.
} 
Second, one concern in most studies that follow the same subjects over a long period of time is attrition. Attrition could bias our Wave 2020 results if the probability of drop-out is correlated with job market outcomes. Out of the 265 subjects from Wave 2013, we reached 230 subjects in Wave 2020. One subject did not allow us to link the data from Wave 2013 to data on his or her further professional career, so we dropped this subject from the Wave 2020 sample. The remaining 229 subjects approved our request to collect data on their professional career and $\mathrm{CV}$, and to link this information to the data from Wave 2013. Hence, 86.4 percent of our subjects from Wave 2013 also participated in Wave 2020. Out of the 229 subjects, one subject was long-term sick between 2013 and 2020 and thus struggled with developing his or her career. Seven other subjects were still studying in 2020. We also dropped these from our Wave 2020 sample, yielding a final sample of 221 subjects who had completed their studies and found their first permanent job after graduation. In Subsection 4.2, we provide further evidence that attrition is of no concern in our study.

\subsection{Classification of Subjects: Finance Interest and Finance Job}

For our analysis, we have to classify subjects according to their professional preferences in 2013 and according to their job placement after graduation. In Wave 2013, we measured professional preferences through the question "To what extent can you imagine working in the following industries in the future?", which had to be answered on a Likert scale from 1 to 7. For our descriptive statistics, we classify subjects according to their response to this question for the financial industry and build three groups of roughly the same size: 73 subjects $(27.5$ percent) indicated one to four points; these will be called "low finance interest subjects"; 93 subjects (35.1 percent) indicated five or six points; we will call them "medium finance interest subjects"; 99 subjects (37.3 percent) indicated seven points; these subjects will be called "high finance interest subjects." For our non-parametric tests and regression analysis, we use subjects' responses on a scale from 1 to 7; we call this variable "finance interest", with higher numbers indicating higher interest.

In Wave 2020, we use our subjects' first permanent job after graduation for classification. This classification is meaningful since the first job is a strong predictor for the industry in which someone spends his or her future professional career (Ellul et al. 2020). This is also the case in our data: On average, the subjects in Wave 2020 had started their first permanent job three years ago, i.e., on average in 2017. Since starting their first permanent job, 96.6 percent had not switched from the financial industry to a non-financial industry or vice versa. All jobs in firms with the NACE (Nomenclature of Economic Activities) codes K64, 
K65, and K66 are classified as jobs in the financial industry. ${ }^{8}$ Overall, out of our 221 subjects in the Wave 2020 sample, 75 (33.9 percent) had their first permanent job after graudation in the financial industry according to the NACE classification. We will call them "finance job subjects" in the following. The remaining 146 subjects (66.1 percent) with first jobs in other industries will be referred to as "non-finance job subjects".

\section{Results}

\subsection{Interest in the Financial Industry and Experimental Behavior (Wave 2013)}

Overall, subjects' behavior in the experimental trust game in 2013 was as follows. As first mover, they sent on average 38.7 percent $(s d=36.5)$ of their endowment. As second mover, they returned on average 20.5 percent $(\mathrm{sd}=17.8)$ of the tripled amount. ${ }^{9}$

We do not find any significant association between finance interest and the amounts sent as a measure of trust. Low finance interest subjects sent on average 38.5 percent ( $\mathrm{sd}=$ 32.5), medium finance interest subjects 37.5 percent $(\mathrm{sd}=35.8)$, and high finance interest subjects 39.9 percent $(s d=40.0)$. There is neither a statistically significant correlation between finance interest and the amount sent in a Jonckheere-Terpstra test ( $p$-value $=0.739$ ) nor in an OLS regression framework, controlling for key characteristics (see Online Appendix, Table A).

However, in terms of the mean share returned as a measure of trustworthiness, we find remarkable differences. As shown in Figure 1, low finance interest subjects returned, on average, 24.4 percent $(\mathrm{sd}=15.7)$, medium finance interest subjects returned 21.5 percent $(\mathrm{sd}=$ 20.5), and high finance interest subjects returned only 16.6 percent $(\mathrm{sd}=16.0)$. The negative relationship between finance interest and the mean share returned is statistically significant (Jonckheere-Terpstra test, $\mathrm{p}$-value $=0.004)$.

\footnotetext{
${ }^{8}$ The description of the industry codes for the respective NACE codes is the following: K64 means "Financial service activities, except insurance and pension funding"; K65 means "Insurance, reinsurance and pension funding, except compulsory social security"; K66 means "Activities auxiliary to financial services and insurance activities." We apply the following exceptions from our classification: Positions in central banks or public organizations or United Nations development aid organizations that belong to NACE codes K64 to K66 were classified as non-finance jobs; four subjects found their first job in these organizations. Excluding them from our analyses does not change our main results.

${ }^{9}$ When we consider only the subsample of subjects who also participated in Wave 2020, we find that first movers sent on average 39.8 percent $(\mathrm{sd}=37.4)$ and second-movers returned 20.0 percent $(\mathrm{sd}=16.8)$. Both figures are statistically indistinguishable from considering all 265 participants in 2013.
} 


\section{Figure 1: Mean share returned, by low, medium, and high finance interest}

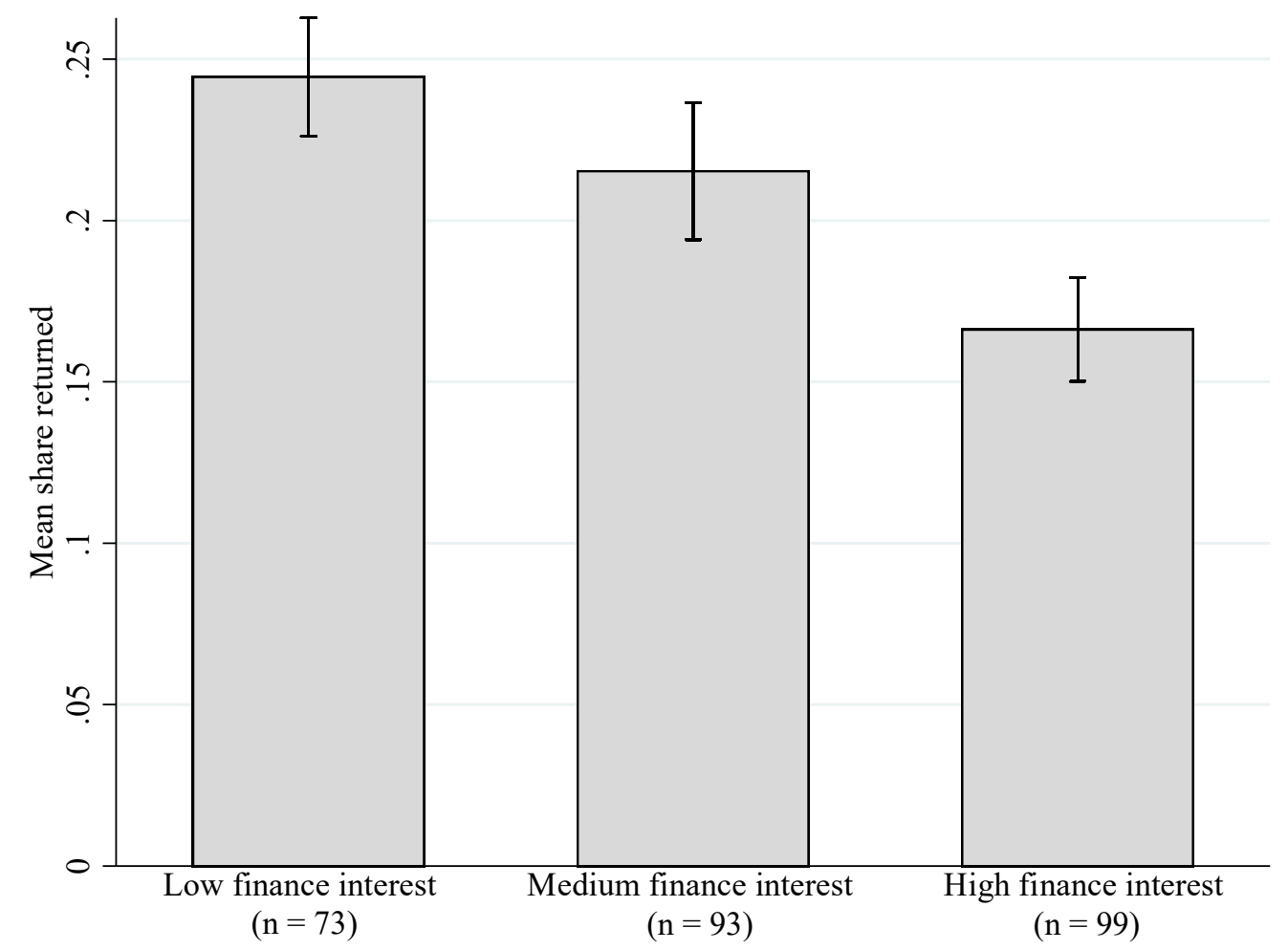

Notes: In Wave 2013, we asked our subjects "To what extent can you imagine working in the following industries in the future?" for 14 different industries, on a Likert scale from 1 ("certainly not") to 7 ("definitely"). Here, we show the average mean share returned for subjects who indicated, for the financial industry, one to four points ("low finance interest"), five or six points ("medium finance interest"), and seven points ("high finance interest"). The whiskers show the standard errors of the mean. The number of observations is in parentheses.

To check the robustness of the relationship between finance interest and the mean share returned, we run an OLS regression in which we regress finance interest on the mean share returned. As shown in column [1a] of Table 1, we find a significantly negative association between finance interest and the mean share returned. The size of the coefficient indicates that each additional unit on the Likert scale from 1 to 7 decreases the mean share returned by 1.8 percentage points, which accounts for almost 10 percent of the overall average return of 20.5 percent.

As shown in column [2a] of Table 1, the main qualitative results are the same when we control for gender, age, and cognitive ability (the score a subject achieved in Raven's Advanced Progressive Matrices). The same is true when we use a Tobit model instead of OLS (see Online Appendix, Table B). As a robustness check, we also use six dummies - one dummy for each value of finance interest from a score of 2 to 7 - as independent variables. Here we find that 
our regression results are mainly driven by those subjects who indicate a " 6 " or a " 7 " in their interest to work in the financial industry (see Online Appendix, Table C). ${ }^{10}$

Table 1: Baseline regressions: mean share returned

\begin{tabular}{lcc|cc}
\hline \hline & \multicolumn{2}{c}{ Panel A } & \multicolumn{2}{c}{ Panel B } \\
Specifications & {$[1 \mathrm{a}]$} & {$[2 \mathrm{a}]$} & {$[1 \mathrm{~b}]$} & {$[2 \mathrm{~b}]$} \\
\hline & $0.299^{* * *}$ & -0.022 & $0.227^{* * *}$ & -0.123 \\
Constant & $(0.032)$ & $(0.109)$ & $(0.014)$ & $(0.101)$ \\
& $-0.018^{* * *}$ & $-0.012^{*}$ & & \\
Finance interest & $(0.006)$ & $(0.006)$ & & \\
& & & $-0.079^{* * *}$ & $-0.075^{* * *}$ \\
Finance job & & & $(0.023)$ & $(0.023)$ \\
& & & & \\
\hline & & & & \\
Subject pool & Yes & Yes & No & No \\
All subjects Wave 2013 & No & No & Yes & Yes \\
All subjects Wave 2020 & & & & \\
& & & & \\
& & & Yes & No \\
Controls & No & 0.076 & 0.050 & 0.123 \\
$\mathrm{R}^{2}$ & 0.034 & 265 & 221 & 221 \\
Sample size & 265 & & \\
\hline \hline
\end{tabular}

Notes: OLS Regression. The dependent variable is the mean share returned as second mover in the trust game. Finance interest is the subjects' response to the question "To what extent can you imagine working in the following industries in the future?" for the financial industry on a Likert-scale from 1 ("certainly not") to 7 ("definitively"). Finance job is a dummy set to one if a subject has the first permanent job after graduation in the financial industry. Controls are age, gender, and the score in the Raven's Advanced Progressive Matrices. Robust standard errors are in parenthesis. ${ }^{*} \mathrm{p}<0.1, * * \mathrm{p}<0.05, * * * \mathrm{p}<0.01$.

\subsection{First Permanent Job and Trustworthiness (Wave 2020)}

Applying the NACE-classification into finance job subjects and non-finance job subjects in 2020, we find no statistically significant difference between both groups in the level of trust as first movers (in the lab experiment in 2013). Non-finance job subjects sent on average 41.5 percent $(s d=36.7)$, while finance job subjects sent on average 36.3 percent $(s d=38.8)$. The difference is not statistically significant (Mann-Whitney test, $p$-value $=0.230$ ), which is in line

\footnotetext{
${ }^{10}$ We use a Tobit model to check the robustness of our results as a large fraction of our subjects has a high interest in working in the financial industry so that our finance interest variable is highly skewed. Using six dummies instead of the variable finance interest is a useful robustness check as we interpret our ordinal finance interest scale in a cardinal way.
} 
with our earlier result that the degree of interest in the financial industry is not related to trust as first movers. So, the behavior as first mover does not depend on whether someone wants to work or actually works in the financial industry. As argued earlier, we consider the degree of trust as of secondary importance, however, because trustworthiness of actors in the financial industry is what counts most for the interaction with customers and the general public. For this reason, we focus in the remainder of the paper on trustworthiness.

The mean share returned as our measure of trustworthiness differs substantially between subjects who get their first job after graduation in the financial industry and those who start working elsewhere. As shown in Figure 2, non-finance job subjects returned on average 22.7 percent $(\mathrm{sd}=16.6)$ of the tripled amount, while finance job subjects returned on average only 14.8 percent $(\mathrm{sd}=16.0)$. The difference - which equals about one third of the non-finance job subjects' trustworthiness - is statistically significant (Mann-Whitney test, p-value $=0.001$ ).

Figure 2: Mean share returned, by finance job

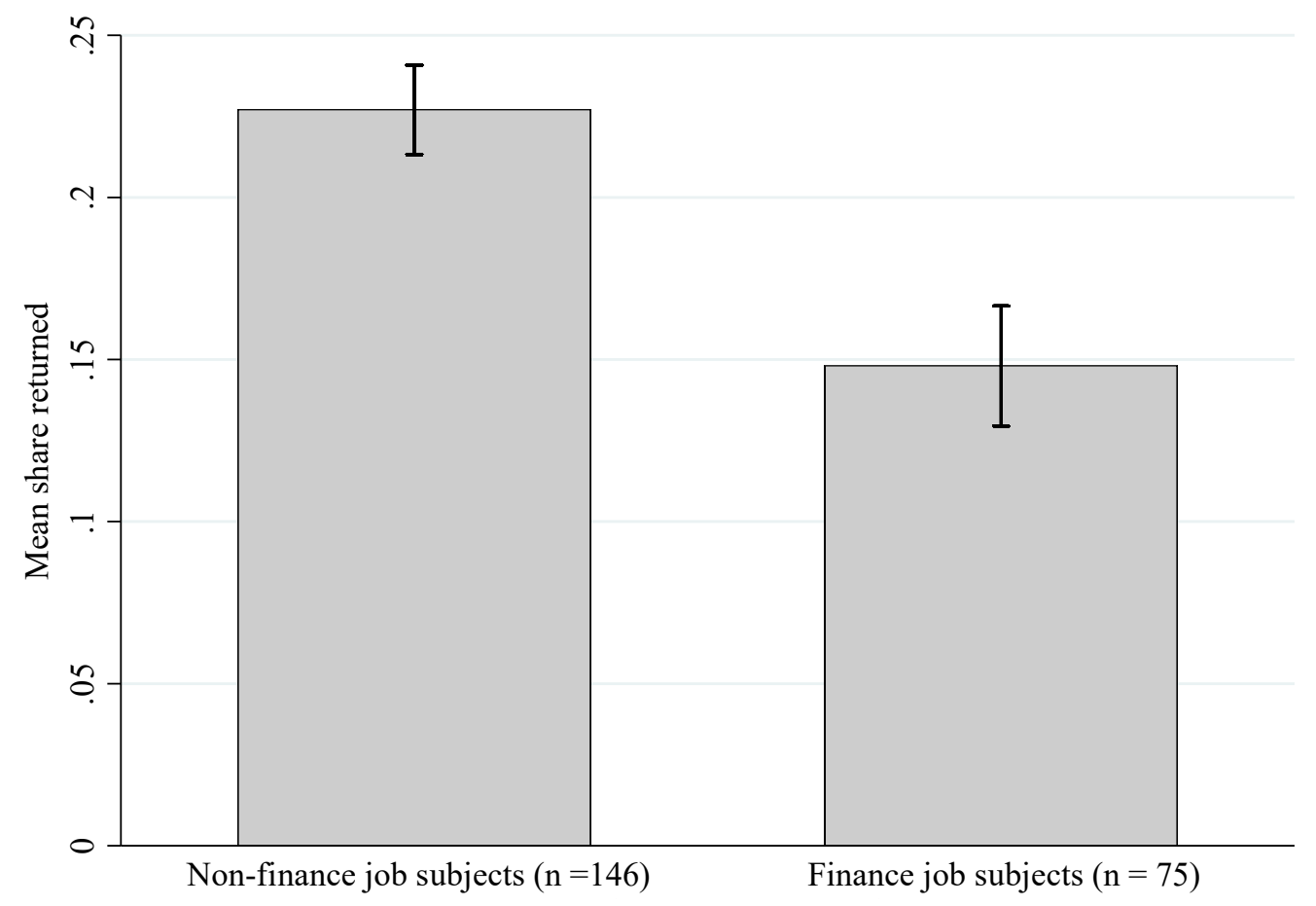

Notes: The figure shows the average mean share returned for subjects with a first job placement after graduation in the financial industry (NACE codes K64 to K66) and for subjects with a job placement after graduation in any other industry based on the data collected in Wave 2020. The whiskers show the standard errors of the mean. The number of observations is in parentheses.

To check the robustness of the non-parametric result, we run an OLS regression in which we regress a dummy for finance job on the mean share returned. The results are presented in column [1b] of Table 1 . We find that finance job subjects return on average 8 percentage points 
less compared to non-finance job subjects. This means that subjects with a first job after graduation in finance return on average a third less than subjects who start working elsewhere. This considerable difference is robust to controlling for age, gender, and cognitive ability (see column [2b] in Table 1).

\subsection{A Closer Look at Finance Interest, Early Career Choices, and Finance Job}

Table 1 has shown a substantial selection of less trustworthy individuals into the financial industry. In the following, we examine in more detail the relation between subjects' professional interests during college days, their specialization choices in education, early professional experiences, and their applications for permanent jobs before getting their first job after graduation. The unusual richness of our data allows us to show that individuals do not end up accidentally in finance, but their early career paths shows characteristic patterns, and these are linked to their trustworthiness.

In the subgroup of high finance interest subjects, 55.4 percent find their first permanent job in the financial industry; for medium finance interest subjects, this number is 26.0 percent, and it drops to only 14.8 percent for low finance interest subjects (Jonckheere-Terpstra test, pvalue $=0.000$ ). This shows that mainly high finance interest subjects choose to work in - and get job offers from - the financial industry, and that our finance interest variable is a good predictor for later job placements in the financial industry. ${ }^{11}$

Even though a strong interest in working in finance in 2013 is a good predictor of whether someone actually gets the first job after graduation in finance, it is interesting to look even more closely at the set of 83 subjects who expressed a high interest (i.e., a "7" on the Likert scale) to work in finance in 2013 and for whom we know the first permanent job. The 46 subjects who started a career in finance returned on average only 11.7 percent $(s d=13.1)$ in the trust game; the other 37 subjects who started working in another industry returned 20.8 percent $(\mathrm{sd}=17.5)$. The difference is very large and statistically significant in a Mann-Whitney test $(p$-value $=0.025)$ and in an OLS regression framework (see Online Appendix, Table D). This indicates that - albeit all 83 subjects expressed a strong interest to work in the financial industry - the job market does not reduce the selection of less trustworthy individuals into the financial industry; if anything, the opposite seems to be the case.

\footnotetext{
${ }^{11}$ Recall that about 30 percent of Goethe University students of business and economics start a career in finance (according to alumni data). The share of students with a high interest in finance who actually get their first job there ( 55.4 percent) is almost twice as large as the average likelihood to find the first job in finance.
} 
To further illustrate how the trustworthiness of subjects depends on the combination of interest in finance during college days and the first permanent job, we compare the 46 subjects who expressed high interest in finance and got their first job there to 52 subjects who indicated low finance interest and starting working outside of finance. The latter group returned on average 26.4 percent $(\mathrm{sd}=15.9)$, which is more than double the rate of 11.7 percent $(\mathrm{sd}=13.1)$ of the former group. The difference is statistically significant in a Mann-Whitney test (p-value $=0.000$ ) and in an OLS regression framework (see Online Appendix, Table E). This comparison of the polar cases suggests very strong behavioral differences between subjects who keep away from the financial industry and subjects who eagerly and successfully pursue a career in finance.

So far, we have only looked into the relation of interest in the financial industry and the actual job placement. Yet, we can dig even deeper by also looking at subjects' career and specialization choices before graduation. We thereby show that high finance interest subjects are not ending up "accidentally" in the financial industry; rather, their career paths show systematic patterns.

Table 2 shows details about the pre-graduation job experience, applications for the first permanent job after graduation, and study background information for all subjects from Wave 2020. Panel A presents averages for all 221 subjects with known first job. Panel B splits up the data contingent on the level of interest in working in the financial industry as expressed in 2013, and panel $\mathrm{C}$ distinguishes between subjects with a first job in finance and those in other industries.

Overall, our subjects spent on average 45.1 weeks in internships, working student jobs or vocational training jobs before graduating; they submitted on average 8.9 applications for their first permanent job, and 71.0 percent of them were enrolled in a master program after finishing their undergraduate studies. We find no significant association between finance interest (in panel B) or finance job (in panel C) and the total amount of pre-graduation job experience, the total number of applications for the first permanent job, and whether subjects are enrolled in a master program. 


\section{Table 2: Subjects' early career and specialization choices - overall and by finance job and finance interest}

\begin{tabular}{c|ccc|c|cc|c} 
Panel A: & \multicolumn{4}{|c|}{ Panel B: Finance interest } & \multicolumn{3}{|c}{ Panel C: Finance job } \\
All subjects & High & Medium & Low & J.-T. ${ }^{\S}$ & Yes & No & M.W. $\$$ \\
Chi & \\
$(\mathrm{n}=221)$ & $(\mathrm{n}=83)$ & $(\mathrm{n}=77)$ & $(\mathrm{n}=61)$ & $\begin{array}{c}\text { p- } \\
\text { value }\end{array}$ & $(\mathrm{n}=75)$ & $(\mathrm{n}=146)$ & p-value
\end{tabular}

\section{Pre-graduation job experience}

Total job experience (in weeks)

Any job experience in the financial industry before graduation (yes / no) Relative job experience in the financial industry (in weeks out of total \#weeks)

45.7

41.2

(28.7)

49.1

$56.1 \%$

$84.3 \%$

$48.1 \%$

0.804

43.3

0.917

$84.3 \%$

$30.1 \%$

$56.3 \%$

$16.7 \%$

$27.9 \%$

0.000

$90.7 \%$

$38.4 \%$

0.000

0.000

$61.1 \% \quad 14.2 \%$

\section{Applications for first permanent job}

Total number of applications

Relative number of

applications in fin. industry

\begin{tabular}{c|ccc|c|cc|c}
8.9 & 9.0 & 11.1 & 6.9 & 0.730 & 9.3 & 8.6 & 0.384 \\
$(13.4)$ & $(13.7)$ & $(16.6)$ & $(9.2)$ & & $(12.6)$ & $(13.8)$ & \\
$24.6 \%$ & $38.3 \%$ & $21.6 \%$ & $6.7 \%$ & 0.000 & $53.5 \%$ & $7.5 \%$ & 0.000
\end{tabular}

\section{Studies}

Bachelor: Finance as major field of study

Enrolled in Master program

\begin{tabular}{l|ll}
$43.6 \%$ & $70.4 \%$ & $38.4 \%$ \\
$71.0 \%$ & $72.3 \%$ & $71.4 \%$
\end{tabular}

$12.3 \%$
$68.9 \%$

0.000
0.600

$65.7 \%$
$72.0 \%$

$32.6 \%$

$70.5 \%$

0.822

\footnotetext{
$\S$ J.-T. denotes Jonckheere-Terpstra-test; M.W. denotes Mann-Whitney U-test.

Notes: The table provides the early career and specialization choices characteristics of all subjects who participated in Wave 2020 (with standard deviations in parentheses). Column 1 provides the characteristics for all 221 subjects; columns $2-5$ provides the characteristics by finance interest (high, medium vs. low finance interest) in Wave 2013; columns 6-8 by the first permanent job after graduation. Total job experience (in weeks) is the number of weeks a subject worked as part of a vocational training program, as a working student or as an intern in a company before graduating (i.e., before or during studies). Any job experience in the financial industry (yes / no) is the share of subjects who have had some job experience in the financial industry before graduating. Relative job experience in the financial industry (share, in weeks out of total \#weeks) is the job experience (vocational training, working student, internships) in the financial industry divided by Total job experience (in weeks). Total number of applications is the total number of applications that subjects submitted after their graduation for their first permanent job. Relative number of applications in the financial industry is the number of applications submitted to firms in the financial industry divided by the Total number of applications. Bachelor: Finance as major field of study is the share of subjects who had finance as the major field of study in their undergraduate studies. Enrolled in Master program is the share of subjects who were at any point in time (before 2020) enrolled in a master program. In Column 5, we report the p-values of a two-sided Jonckheere-Terpstra test. In Column 8, we report p-values of either two-sided Mann-Whitney rank-sum tests (for non-binary variables), or Chi-square tests (for binary variables). The number of observations is 221 , with the following exceptions: Two subjects had no job experience and are dropped in the analysis on relative job experience in the financial industry. Total number of applications: 24 subjects did not know the total number of applications, or were not willing to provide us with the data; we omitted those subjects in the respective analysis. For the analysis of Relative job experience in the financial industry (share, in weeks) we omitted 24 subjects who did not submit any applications (e.g. because they already worked as an intern in the respective firm). Bachelor: Finance as major field of study: For ten subjects, we do not know the major field of study; the subjects are dropped in the respective analysis
} 
However, we find significant differences between the subsamples of subjects in panels $\mathrm{B}$ and $\mathrm{C}$ of Table 2 when we distinguish between early career and specialization choices that are more or less likely to lay a foundation for a career in the financial industry. Looking first at the results for finance interest in panel B of Table 2, we see three noteworthy findings. First, a large majority of high finance interest subjects (84.3 percent) have pre-graduation job experience in the financial industry. In contrast, job experience in the financial industry is much less pronounced among low finance interest subjects; only 27.9 percent of them collected professional experience in this industry. In line with this, high finance interest subjects also acquire much more relative pre-graduation job experience, as measured by the share of weeks spent in financial companies (relative to the total number of weeks with pre-graduation job experience), compared to low finance interest subjects (56.3 percent vs. 11.4 percent). Second, high finance interest subjects submit a larger share of their applications (38.3 percent) for their first permanent job to firms from the financial industry. In contrast, low finance interest subjects only submit 6.7 percent of their applications to firms from the financial industry. Third, the majority of high finance interest subjects (70.4 percent) chose "finance" as their major field of study during their undergraduate studies. Among low finance interest subjects, only 12.3 percent of subjects chose such a major.

The results for subjects with a first job in finance and those in other industries are presented in Panel $\mathrm{C}$ of Table 2. The main qualitative results are the same as for finance interest. Subjects with their first permanent job in finance have considerably more often any pregraduation job experience in the financial industry ( 90.7 percent versus 38.4 percent), spend a larger fraction of their pre-graduation job experience in the financial industry $(61.1$ percent versus 14.2 percent), submit many more of their applications to the financial industry (53.5 percent versus 7.5 percent), and choose more often finance as their major field in their Bachelor study (65.7 percent versus 32.6 percent). All of these differences are highly significant ( $p$-value $<0.001$ ), showing that subjects who get their first permanent job after graduation in the financial industry have markedly different early career paths and specialization choices. In the previous subsection, we have already seen that they are much less trustworthy as well. In the next subsection, we analyze whether they also differ in personal characteristics from those who find their first job outside of the financial industry.

\subsection{Personal Characteristics}

Table 3 shows data on age, gender, risk and time preferences, cognitive abilies, as well as work values (Ronen 1994). Again, panel A shows the overall averages for all subjects, and panels B 
and $\mathrm{C}$ present averages (and standard deviations) for the three categories of finance interest (high, medium and low) and whether or not someone had the first job in finance.

Table 3: Characteristics of our subjects, overall and by finance interest and finance job

\begin{tabular}{|c|c|c|c|c|c|c|c|c|}
\hline & \multirow{2}{*}{$\begin{array}{l}\text { Panel A: All } \\
\text { subjects } \\
\quad(n=265)\end{array}$} & \multicolumn{4}{|c|}{ Panel B: Finance interest } & \multicolumn{3}{|c|}{ Panel C: Finance job } \\
\hline & & $\begin{array}{l}\text { High } \\
(\mathrm{n}=99)\end{array}$ & $\begin{array}{l}\text { Medium } \\
\qquad(\mathrm{n}=93)\end{array}$ & $\begin{array}{l}\text { Low } \\
(\mathrm{n}=73)\end{array}$ & $\begin{array}{c}\text { J.-T. } \\
\text { p- } \\
\text { value }\end{array}$ & $\begin{array}{c}\text { Yes } \\
(\mathrm{n}=75)\end{array}$ & $\begin{array}{c}\text { No } \\
(n=146)\end{array}$ & $\begin{array}{c}\mathbf{M W}^{\S} / \\
\mathbf{C h i}^{2} \\
\text { p- } \\
\text { value }\end{array}$ \\
\hline Age & $22.0(2.4)$ & $22.2(2.4)$ & $21.5(2.1)$ & $22.6(2.7)$ & 0.371 & $22.1(2.4)$ & $22.0(2.4)$ & 0.639 \\
\hline Female & $51.1 \%$ & $35.4 \%$ & $51.6 \%$ & $76.7 \%$ & 0.000 & $40.0 \%$ & $53.4 \%$ & 0.059 \\
\hline Risk preferences & $5.3(2.1)$ & $5.9(2.0)$ & $5.4(1.9)$ & $4.4(2.1)$ & 0.000 & $5.6(1.0)$ & $5.2(1.1)$ & 0.197 \\
\hline Patience & $5.1(2.4)$ & $5.2(2.6)$ & $4.8(2.4)$ & $5.1(2.3)$ & 0.507 & $5.2(1.5)$ & $5.1(1.4)$ & 0.623 \\
\hline Raven's score & $7.4(2.2)$ & $7.4(2.2)$ & $7.3(2.0)$ & $7.2(2.2)$ & 0.340 & $7.3(2.3)$ & $7.5(2.1)$ & 0.442 \\
\hline Items on work values & & & & & & & & \\
\hline Working conditions & $5.6(1.1)$ & $5.7(1.1)$ & $5.6(1.0)$ & $5.6(1.1)$ & 0.083 & $5.7(1.2)$ & $5.6(1.0)$ & 0.139 \\
\hline Work-life balance & $5.9(1.4)$ & $5.6(1.6)$ & $6.0(1.2)$ & $6.1(1.0)$ & 0.031 & $5.7(1.5)$ & $6.0(1.3)$ & 0.147 \\
\hline Distance: work \& home & $5.7(1.2)$ & $5.5(1.4)$ & $5.6(1.2)$ & $5.7(1.2)$ & 0.752 & $5.4(1.4)$ & $5.8(1.2)$ & 0.075 \\
\hline Job security & $5.7(1.4)$ & $5.5(1.6)$ & $6.1(1.1)$ & $5.8(1.3)$ & 0.448 & $5.5(1.6)$ & $5.8(1.4)$ & 0.069 \\
\hline Income & $5.7(1.2)$ & $6.3(0.9)$ & $5.6(1.2)$ & $5.2(1.2)$ & 0.000 & $6.0(1.0)$ & $5.5(1.2)$ & 0.003 \\
\hline Benefits & $4.2(1.7)$ & $4.8(1.6)$ & $4.0(1.6)$ & $3.7(1.6)$ & 0.000 & $4.6(1.5)$ & $4.0(1.7)$ & 0.017 \\
\hline Relationship co-workers & $6.2(1.0)$ & $6.3(1.0)$ & $6.2(1.0)$ & $6.3(1.0)$ & 0.583 & $6.1(1.0)$ & $6.2(1.1)$ & 0.285 \\
\hline Relationship supervisor & $6.0(1.1)$ & $6.1(1.1)$ & $6.1(1.1)$ & $5.9(1.1)$ & 0.188 & $6.0(1.1)$ & $6.0(1.1)$ & 0.831 \\
\hline Career opportunities & $6.2(1.0)$ & $6.6(0.6)$ & $6.2(0.9)$ & $5.9(1.2)$ & 0.000 & $6.3(0.9)$ & $6.1(1.0)$ & 0.071 \\
\hline Training & $6.0(1.1)$ & $6.2(1.2)$ & $5.9(0.9)$ & $6.0(1.0)$ & 0.059 & $5.9(1.3)$ & $6.0(1.0)$ & 0.828 \\
\hline Autonomy & $5.6(1.2)$ & $5.7(1.2)$ & $5.4(1.3)$ & $5.7(1.1)$ & 0.730 & $5.8(1.1)$ & $5.5(1.3)$ & 0.170 \\
\hline Personality development & $5.6(1.2)$ & $5.5(1.2)$ & $5.6(1.3)$ & $5.8(1.2)$ & 0.091 & $5.6(1.1)$ & $5.6(1.3)$ & 0.397 \\
\hline Challenging tasks & $5.7(1.1)$ & $5.7(1.0)$ & $5.5(1.2)$ & $5.8(1.0)$ & 0.889 & $5.9(0.9)$ & $5.6(1.2)$ & 0.056 \\
\hline $\begin{array}{l}\text { Reputation of the } \\
\text { employer }\end{array}$ & $5.2(1.5)$ & $5.6(1.3)$ & $5.0(1.4)$ & $5.1(1.5)$ & 0.005 & $5.3(1.5)$ & $5.2(1.5)$ & 0.840 \\
\hline
\end{tabular}

$\S$ J.-T. denotes Jonckheere-Terpstra-test; MW denotes Mann-Whitney U-test.

Notes: The table shows characteristics of our subject pool (and standard deviations in parentheses). Column 1 provides the characteristics for all subjects $(\mathrm{n}=265)$; columns 2 to 5 by finance interest (high, medium vs. low finance interest, $\mathrm{n}=265)$; column 6 to 8 by the first permanent job after graduation (finance versus non-finance, $\mathrm{n}=221$ ). Age is a subject's age in 2013; Risk preference is the self-reported willingness to take risk on a scale between 0 and 10 (Dohmen et al. 2011); Patience is self-reported patience on a scale between 0 and 10 (Vischer et al. 2013). Raven's score is the score a subject achieved in Raven's Advanced Progressive Matrices (Bors and Stokes 1998). The work values listed under Items on work values are based on Ronen (1994). Subjects were asked to rate on a scale between 1 (not attractive) to 7 (highly attractive) how important different characteristics of jobs are for an attractive job. In Column 5, we report the p-values of a two-sided Jonckheere-Terpstra test to measure the of the finance interest variable (using the 7-scale score). In Column 8, we report p-values of either two-sided Mann-Whitney ranksum tests (for non-binary variables), or Chi-square tests (for binary variables), to measure the influence of having a job in the financial industry or elsehwere. 
Overall, 51.1 percent of our subjects in Wave 2013 were female, and at that time they were 22 years old on average. The self-reported willingness to take risks was 5.3 (on a scale between 0 and 10), and self-reported patience was 5.1 (on a scale between 0 and 10). As a measure of cognitive abilities, subjects had an average Raven score of 7.4 (on a scale between 0 and 12). The most important self-reported work values were career opportunities and the relationships to co-workers.

Looking at panels $\mathrm{B}$ and $\mathrm{C}$, we note that high finance interest and finance job subjects are more often male, as is a common finding in the literature on gender representation in finance (Adams et al. 2016). Interestingly, cognitive abilities are not associated with finance interest and finance jobs. Therefore, it does not seem to be the case that "smarter" individuals get more often jobs in the financial industry. Risk preferences are different between subjects with a high and low interest in finance, but not between those who end up in finance as their first job and others who get their job elsewhere (compare panels B and C). Concerning work values, we see only two major differences (that are significant at the 5\%-level) between subjects with a job in the financial industry and those in other industries: subjects in the financial industry appreciate income and benefits from the job much more than subjects working in other industries. Other than that, those two groups do not differ noticeably in their work values (see panel C of Table $3) .^{12}$

\section{Robustness Checks}

We now proceed to several robustness checks in which we highlight the potential influence of exposure to the financial industry, the sensitivity of our data with respect to how we classify subjects into finance job and non-finance jobs, and the potential effect of attrition from Wave 2013 to Wave 2020.

\subsection{Exposure and Selection}

Our main finding from the previous section - that subjects who find their first permanent job in the financial industry are less trustworthy than those selecting into other industries - would be, in principle, also compatible with the following interpretation. As we have seen in Subsection 3.3, subjects who start to work in the financial industry after graduation have had much more experience in this industry prior to graduation (e.g., in the form of internships).

\footnotetext{
${ }^{12}$ This is also the case if we control for multiple hypothesis testing (List et al. 2019).
} 
Therefore, their exposure to the business culture in the financial industry might have made them less trustworthy already when we measured trustworthiness in Wave 2013.

To examine this alternative interpretation, we run two robustness checks of our baseline regressions from Table 1. First, we include only subjects who were in the first three semesters of their undergraduate studies at the point in time when they participated in Wave 2013. Here we exploit the fact that the basic courses in business and economics at Goethe-University Frankfurt are the same for all students, independent of their interest in working in the financial industry. In particular, this means that these subjects had not taken yet any specialization course in finance. Table 4 shows that the estimated coefficients for finance interest (in panel A) and finance job (in panel B) on trustworthiness are of comparable magnitude as in Table 1, and in particular they show the same significance levels. Exposure to specialization courses in finance (that subjects beyond the third semesters typically have) does not matter for the relation between trustworthiness and finance job, respectively finance interest.

Table 4: Regression results, focusing on the subsample of subjects who are in the first three semester of their studies

\begin{tabular}{lcc|cc}
\hline \hline & \multicolumn{2}{c}{ Panel A } & \multicolumn{2}{c}{ Panel B } \\
Specifications & {$[1 \mathrm{a}]$} & {$[2 \mathrm{a}]$} & {$[1 \mathrm{~b}]$} & {$[2 \mathrm{~b}]$} \\
\hline & & & & \\
Constant & $0.314^{* * *}$ & -0.139 & $0.201^{* * *}$ & -0.089 \\
& $(0.041)$ & $(0.150)$ & $(0.017)$ & $(0.138)$ \\
Finance interest & $-0.023^{* * *}$ & $-0.018^{* *}$ & & \\
& $(0.007)$ & $(0.007)$ & & \\
Finance job & & & $-0.068^{* *}$ & $-0.061^{* *}$ \\
& & & $(0.029)$ & $(0.030)$ \\
& & & & \\
Subject pool & & & & \\
All subjects Wave 2013 & Yes & Yes & No & No \\
All subjects Wave 2020 & No & No & Yes & Yes \\
& & & & \\
\hline & & & & \\
Controls & No & Yes & No & Yes \\
$\mathrm{R}^{2}$ & 0.046 & 0.090 & 0.042 & 0.128 \\
Sample size & 153 & 153 & 127 & 127 \\
\hline \hline
\end{tabular}

Notes: Modified version of our baseline regressions from Table 1. Here, we focus on subjects who were in the first, second or third semester of their studies at the point in time when we conducted Wave 2013. Robust standard errors are in parenthesis. ${ }^{*} \mathrm{p}<0.1, * * \mathrm{p}<0.05, * * *$ $\mathrm{p}<0.01$. 
Table 5: Regression results, excluding all subjects who already had job experience in the financial industry before we conducted Study 2013

\begin{tabular}{lcc|cc}
\hline \hline & \multicolumn{2}{c}{ Panel A } & \multicolumn{2}{c}{ Panel B } \\
Specifications & {$[1 \mathrm{a}]$} & {$[2 \mathrm{a}]$} & {$[1 \mathrm{~b}]$} & {$[2 \mathrm{~b}]$} \\
\hline & & & & \\
Constant & $0.299^{* * *}$ & -0.114 & $0.248^{* * *}$ & -0.123 \\
& $(0.036)$ & $(0.145)$ & $(0.015)$ & $(0.121)$ \\
Finance interest & $-0.016^{* *}$ & $-0.014^{* *}$ & & \\
& $(0.007)$ & $(0.007)$ & & \\
Finance job & & & $-0.121^{* * *}$ & $-0.112^{* * *}$ \\
& & & $(0.028)$ & $(0.029)$ \\
& & & & \\
Subject pool & & & & \\
All subjects Wave 2013 & Yes & Yes & No & No \\
All subjects Wave 2020 & No & No & Yes & Yes \\
& & & & \\
\hline & & & & \\
Controls & No & Yes & No & Yes \\
$\mathrm{R}^{2}$ & 0.028 & 0.086 & 0.100 & 0.182 \\
Sample size & 187 & 187 & 153 & 153 \\
\hline \hline
\end{tabular}

Notes: Modified version of our baseline regressions from Table 1. Here, we focus on subjects who had no prior job experience in the financial industry (e.g. through internships) at the point in time when we conducted Wave 2013. Robust standard errors are in parenthesis. * $\mathrm{p}<0.1, * * \mathrm{p}<0.05, * * * \mathrm{p}<0.01$.

Of course, it could matter even more whether someone had already some (albeit shortterm) experience in the financial industry (through internships and the like) before Wave 2013. While most of our high finance interest subjects and finance job subjects only gained job experience in the financial industry after 2013, some had been working as interns before. Therefore, we present in Table 5 the results of our baseline regression when we exclude all subjects who already had job experience in the financial industry before they played the trust game in 2013. Table 5 shows that this exclusion those does not matter for our main results. Subjects with a strong interest in finance (panel A) and those who get their first permanent job in the financial industry (panel B) are significantly less trustworthy than others. While the estimated coefficients in panel A of Table 5 are remarkable close to those in panel A of Table 1 , we see that the coefficients for finance job in panel B of Table $5(-0.121$, respectively -0.112$)$ are even slightly larger in absolute terms than those in panel B of Table $1(-0.079$, respectively 0.075). So, looking only at subjects without any prior experience in the financial industry, the 
negative relation between trustworthiness and getting a job in the financial industry later on is even stronger.

\subsection{Classification of Which Jobs are Finance Jobs}

To ensure that our results are robust to our finance job classification, we vary the classification in a number of ways. First, we have 34 subjects in our sample who completed a vocational training before commencing their studies. We interpret vocational training as part of their education and not as their first job. This assumption has little consequences for our classification. From the 34 subjects with vocational training, 14 completed it in industries other than the financial industry; none of them had the first job after graduation in the financial industry. From the 20 subjects with vocational training in the financial industry, 17 found their first job after graduation in the financial industry. When we exclude the remaining three subjects from our sample, our results remain unchanged.

Second, we have 16 students who changed their field of study after Wave 2013 had been conducted. ${ }^{13}$ Our results remain unchanged when we drop these subjects from our sample (see Online Appendix, Table F).

Third, we have subjects who switched their employer after starting in their first permanent job. Although subjects were on average already working for around three years (mean $=35.4$ months, $\mathrm{sd}=22.4$ ), only a minority of them had switched their employer at least once, and even less so across industries: 23 out of the 75 finance job subjects switched their employer before we completed Wave 2020; 20 of them switched to another employer in the financial industry, and three left the financial industry. Among the 146 subjects in non-financial industries, only five subjects switched from a non-financial to a financial company. When we adjust the finance job classification for the eight subjects who switched between the financial and non-financial industries, our results remain unchanged (see Online Appendix, Table G).

Finally, we study whether the job selection based on trustworthiness also exists for other industries. Table $\mathrm{H}$ in the Appendix provides an overview of all industries in which at least three subjects had found their first permanent job after graduation. Consistent with alumni data from Goethe University Frankfurt, firms in the financial industry are by far the most important employers in our sample: 33.9 percent of our Wave 2020 subjects have their first permanent job in the financial industry. Among the top three sectors are also consulting (12.2 percent),

\footnotetext{
${ }^{13}$ The subjects switched from business and economics to computer science (three subjects), educational science (two subjects), geography (two subjects), biology (two subjects), medicine, chemistry, psychology, law (one subject each); two subjects started a vocational training.
} 
and auditing ( 7.7 percent). As a robustness check, we rerun our baseline regression from Table 1 for finance jobs, adding one dummy for the other two large sectors (consulting, auditing) into which students selected after their graduation. All other sectors are used as the benchmark. Our main results for finance job subjects remain unchanged (see Online Appendix, Table I). We find no significant effects on trustworthiness for the other two large industries. Moreover, the differences between the finance job coefficient and the consulting and audit job coefficients are statistically significant in both regressions (Wald test, all p-values $<0.040$ ).

\subsection{Attrition}

As already mentioned in Subsection 2.3, a potential concern for our results could be the attrition between Wave 2013 and Wave 2020. Attrition would bias our results if the probability of dropout was correlated with job market outcomes.

We do not believe that attrition is a concern for our results, however. First, attrition in our study is rather low: 86.4 percent of our subjects from Wave 2013 also participated in Wave 2020. Second, we have (by design) no attrition when we analyze the association between experimental behavior and finance interest in Wave 2013, and we saw in Subsection 3.3 that finance interest is an important predictor for job market placements. Third, when we compare data from Wave 2013 on the most important observable and measured characteristics (age, gender, cognitive ability, finance interest, pre-graduation job experience) between subjects who participated in Wave 2020 and those who dropped out, we find no statistical differences (MannWhitney tests, all p-values $>0.130$ ), with one exception. Women are significantly more likely to drop out than men.

To examine the potential effects of attrition in more detail, we perform several simulations as follows: We use the Wave 2020 data to predict the probability that a subject's first permanent job is in the financial industry, based on subject's observables and characteristics (see Online Appendix, Table J). Using these results, we estimate for each of the 35 drop-out subjects from Wave 2013 the probability that his or her first permanent job is in the financial industry. The average estimated probability is 32.8 percent $(\mathrm{sd}=17.2) ; 13$ subjects have a probability below 25 percent, 12 subjects a probability between 25 and 45 percent, and 10 subjects a probability of 45 percent or higher. Using these estimated probabilities, we then run a battery of robustness checks of our baseline regression for finance job (as in panel B of Table 1). In these robustness checks, we include of course all subjects who did not drop out. Additionally, we include all drop-out subjects, and vary in eleven different regressions whether or not they are considered as a finance job subject or a non-finance job subject. More precisely, 
we start with the assumption that all drop-out subjects are finance job subjects. This is scenario 1 in Table $\mathrm{K}$ in the Online Appendix, which implies a cut-off rule of zero percent. In Scenario 2 , the finance job dummy is set to one for all drop-out subjects who have a probability of $10 \%$ or higher to have the first job in the financial industry (otherwise zero). Then we move in 10percentage points steps until we get to a cut-off of 100 percent where all drop-outs are classified as non-finance job subjects. As becomes clear from Table $\mathrm{K}$ in the Appendix, we find that in all eleven regressions our main coefficient of interest is economically and statistically significant and very close to the coefficient reported in column [2b] of Table 1. So, overall, our evidence provides strong support for the persistence of our main qualitative results even if we had a zero drop-out rate.

\section{Further Evidence for Selection on Social Preferences}

Before concluding, we would like to provide some further supportive evidence for selection on social preferences. This helps us to address also a potential concern that our results could be unique to the study location or to the dimension of social preferences that we evaluated. To relax this concern, we use data from an unrelated study (Heinz and Schumacher 2017), in which we measured professional preferences and experimental behavior in a public-goods game. This study was conducted with 515 students from all study fields at the University of Cologne (which has the biggest business and economics department in Germany) and the University of Düsseldorf in 2014. ${ }^{14}$ Behavior in the public goods game measures subjects' willingness to cooperate in groups. This is another trait of social preferences (different from trustworthiness) that is also important in the financial industry. ${ }^{15}$

In the experiment, subjects are randomly matched into groups of three participants (see the instructions in Online Appendix V). Following Fischbacher and Gächter (2010) and Fischbacher et al. (2001), each subject initially holds 20 tokens, which he or she can either keep

\footnotetext{
${ }^{14}$ In particular, 347 subjects were students at the University of Cologne, 168 at the University of Düsseldorf. For the experiment, we used an adapted version of the z-Tree code from Fischbacher and Gächter (2010). Each session lasted about 90 minutes. The exchange rate was 0.35 Euros for each token. On average, subjects earned 34.10 Euros (including a show-up fee of 23 Euros) at the University of Cologne and 22.50 Euros (including a show-up fee of 4 Euros) at the University of Düsseldorf. The variation in payments is because the rest of the experimental protocol was different in Cologne and Düsseldorf; see Heinz and Schumacher (2017) for details. We show in our regression analysis that controlling for the study location (Cologne or Düsseldorf) does not affect our results.

${ }^{15}$ Several papers have shown that cooperation in the public goods game predicts cooperative behavior outside the laboratory; see Rustagi et al. (2010) for common resource management, Algan et al. (2016) for open source software development, and Englmaier and Gebhardt (2016) for workplace performance.
} 
or contribute to the public good of the group. Denote by $g_{i}$ the number of tokens that subject $i$ contributes to the public good. The payoff of group member $i$ is then given by

$$
\pi_{i}=20-g_{i}+0.6 \sum_{j=1}^{3} g_{j} \text {. }
$$

The optimal strategy for money-maximizing subjects is to free ride $\left(g_{i}=0\right)$, while the maximization of the group-payoff would dictate to contribute everything $\left(g_{i}=20\right)$. In our oneshot game, subjects make a single decision about how many of the 20 tokens they want to contribute to the public good. ${ }^{16}$

Using the same scale for one's interest in working in the financial industry as in our Wave 2013 (with the Likert scale ranging from 1 to 7), we have 85 subjects with high finance interest (16.5 percent), 133 with medium finance interest (25.8 percent), and 297 with low finance interest (57.6 percent). This distribution shows that the interest to work in the financial industry is significantly higher among subjects in Frankfurt than in the sample from Cologne and Düsseldorf (Mann-Whitney test, $\mathrm{p}$-value $=0.000$ ). This reflects that the sample from Cologne and Düsseldorf is from different study fields, and that neither Cologne nor Düsseldorf are as interesting as Frankfurt for individuals who would like to work in the financial industry.

Nevertheless, the experimental results mirror those from our Wave 2013 and provide further support for a relationship between social preferences and one's interest in a career in the financial industry. Low finance interest subjects contributed on average 10.2 tokens ( $\mathrm{sd}=$ 6.5), medium finance interest subjects contributed on average 9.2 tokens ( $\mathrm{sd}=6.8)$, and high finance interest subjects contributed only 7.6 tokens $(\mathrm{sd}=6.9)$. This negative relationship between finance interest and contributions is significant (Jonckheere-Terpstra test, p-value $0.000)$.

To confirm this result, we run a modified version of our baseline regression, using the contribution to the public good as dependent variable. As shown in Table 6, we find a significant negative effect of finance interest on contributions. To illustrate the magnitude of the effect, note that the median response on the Likert scale for interest in working in the financial industry is 4 in the sample from Cologne and Düsseldorf. This implies that someone with a high interest (a " 7 " on the scale) is estimated to contribute about 20 percent less to the public than the median subject. The effect size is robust to controlling for age, gender, cognitive

\footnotetext{
${ }^{16}$ Subsequently, subjects also made a "conditional contribution" to the public good (i.e., a contribution for each of the 21 possible average contribution levels of the other group members). They also played the game for ten consecutive rounds. Here, we only discuss the "unconditional contribution" in the one-shot game because contributions in the repeated game are confounded by others' contributions and learning.
} 
ability, location of the experiment (Cologne or Düsseldorf), and whether the subject was a business or economics student.

Table 6: Regression result: contributions in the public goods game

\begin{tabular}{lccc}
\hline \hline Specifications & $(1)$ & $(2)$ & $(3)$ \\
\hline \multirow{2}{*}{ Constant } & & & \\
& $11.128^{* * *}$ & $6.691^{* *}$ & $7.275^{* * *}$ \\
Finance interest & $(0.561)$ & $(2.741)$ & $(2.754)$ \\
& $-0.432^{* * *}$ & $-0.402^{* * *}$ & $-0.319^{* *}$ \\
& $(0.132)$ & $(0.137)$ & $(0.153)$ \\
Controls I & No & Yes & Yes \\
Controls II & No & No & Yes \\
$\mathrm{R}^{2}$ & 0.021 & 0.028 & 0.029 \\
Sample size & 515 & 515 & 513 \\
\hline \hline
\end{tabular}

Notes: OLS regression, similar to our baseline regression for finance interest (Table 1, Panel A). The dependent variable is the unconditional contribution in the one-shot public goods game. The independent variable is Finance interest (ranging from 1 to 7). Controls are age, gender, and the scores in Raven's Advanced Progressive Matrices. Controls II is a dummy set to one if a student is a business/economics student and a dummy set to one (zero) if the experiment took place in Cologne (Düsseldorf). Two subjects are excluded in Specification 3 as we do not know their field of study. Robust standard errors are in parenthesis. ${ }^{*} \mathrm{p}<0.1,{ }^{* *} \mathrm{p}<0.05, * * *$ $\mathrm{p}<0.01$.

Although we do not have information about the 515 students' first job placement, we have seen in Subsection 3.3 that an interest in working in the financial industry during one's college days is a significant predictor of actual job placement. So, the evidence from the public goods game suggests that there might also be a relationship between the willingness to cooperate in groups and selection into the financial industry. Moreover, the results from the public goods game addresses potential concerns that our results are only confined to Frankfurt, or that they depend on the skewed distribution of the interest to work in the financial industry as was the case in Frankfurt. In Cologne and Düsseldorf, the distribution is skewed in the opposite direction, but yields qualitatively similar results. 


\section{Conclusion}

Financial companies frequently emphasize the role of trust in their business (Gennaioli et al. 2015), meaning that they want to be seen as trustworthy interaction partners for their clients in particular and the society at large. Nevertheless, widespread misconduct, corporate scandals, and the low reputation of the financial industry in the public indicate that there may be a trustworthiness problem. One potential explanation for this problem could be the selection of less trustworthy (or generally speaking: less pro-social) individuals into the finance workforce. To address this explanation, it is not sufficient to compare the trustworthiness or social preferences of people working within the financial industry to those working in other areas. Rather, it is necessary to follow students' professional interests during their college days and the transition into the first permanent job after graduation. Since the industry in which someone starts the first permanent job has long-term consequences - because 10 years after entering the job market, around $80 \%$ of subjects still work in the same industry (Ellul et al. 2020) - knowing the first job placement after graduation allows to link social preferences during college days and job selection into specific industries.

Our long-term project has measured students' trustworthiness early on in their college days (in Wave 2013) and has identified their first permanent job placement several years later (in Wave 2020). We have found that individuals who, at the start of their studies, express a strong interest to work in the financial industry are substantially less trustworthy than individuals with other professional goals. Importantly, this relationship persists if we consider actual job market placements. Individuals who find their first job after graduation in the financial industry are significantly less trustworthy than individuals who commence their career in other industries. The former group returned on average one third less than the latter group in our experimental trust game. Thus, the financial industry does not seem to screen out less trustworthy individuals. If anything the opposite seems to be the case: Even among students who are highly motivated to work in finance after graduation, those who actually start their career in finance are significantly less trustworthy than those who work elsewhere. Similar to our main results on trustworthiness, we have also reported a negative relationship between willingness to cooperate (in a public goods game) and students' interest in working in the financial industry. We take this as supportive evidence that selection on social preferences into the financial industry is not only confined to the core of our paper, i.e., trustworthiness.

Given our results on negative selection on social preferences into the financial industry and the large informational asymmetries in this industry, it seems obvious that consumer 
protection and the promotion of product transparency are very important for the financial industry, arguably even more so than in other industries. Yet, despite attempts to protect consumers and make products more transparent, the past decade has seen a multitude of scandals and a plethora of misconduct (Egan et al. 2019). This raises the question how negative selection on social preferences could potentially be avoided in the future. Given that our results suggest that financial companies themselves do not screen out less trustworthy subjects, it is unlikely that the financial industry will address this issue itself by putting more weight (in the hiring process, not only in public statements) on prosocial preferences of future employees. This suggests that policy interventions might be needed to change incentive structures in the financial industry (Bell and Van Reenen 2014, Eufinger and Gill 2017) such that it attracts more trustworthy and prosocial candidates in the future. We consider it an important agenda for future research to examine how this could be achieved. 


\section{References}

Adams, Renée, Brad Barber, and Terrance Odean (2016): "Family, values, and women in finance," Working Paper.

Algan, Yann, Yochai Benkler, Emeric Henry, and Jérôme Hergueux (2016): "Social motives and the organization of production: experimental evidence from open source software," Working Paper.

Balafoutas, Loukas, Adrian Beck, Rudolf Kerschbamer, and Matthias Sutter (2013): "What drives taxi drivers? A field experiment on fraud in a market for credence goods," Review of Economic Studies, 80(3), 876-891.

Baran, Nicole, Paola Sapienza, and Luigi Zingales (2010): “Can we infer social preferences from the lab? Evidence from the trust game," NBER Working Paper No. 15654.

Barfort, Sebastian, Nikolaj Harmon, Frederik Hjorth, and Asmus Leth Olsen (2019): "Sustaining honesty in public service: The role of selection," American Economic Journal: Economic Policy, 11(4), 96-123.

Bell, Brian, and John Van Reenen (2014): “Bankers and their bonuses," Economic Journal 124(574), F1-F21.

Berg, Joyce, John Dickhaut, Kevin McCabe (1995): "Trust, reciprocity, and social history," Games and Economic Behavior, 10(1), 122-142.

Bors, Douglas, and Tonya Stokes (1998): "Raven's advanced progressive matrices: Norms for first-year university students and the development of a short form," Educational and Psychological Measurement, 58(3), 382-398.

Boustanifar, Hamid, Everett Grant, and Ariell Reshef (2018): "Wages and human capital in finance: International Evidence, 1970-2011," Review of Finance, 22(2), 699-745.

Brandts, Jordi, and Gary Charness (2011): “The strategy versus direct response method: a first survey of experimental comparisons," Experimental Economics, 14, 375-398.

Célérier, Claire, and Boris Vallée (2019): "Returns to talent and the finance wage premium," Review of Financial Studies, 32(10), 4005-4040.

Cohn, Alain, Ernst Fehr, and Michel André Maréchal (2014a): “A culture of cheating? Dishonesty and business culture in the banking industry," Nature, 516, 86-89.

Cohn, Alain, Ernst Fehr, and Lorenz Goette (2014b): "Fair wages and effort: Evidence from a field experiment," Management Science, 61(8), 1777-1794.

Cohn, Alain, Ernst Fehr, and Michel André Maréchal (2019): "Selective participation may undermine replication attempts," Nature, 575, E1-E2. 
Dohmen, Thomas, Armin Falk, David Huffman, Uwe Sunde, and Gert Wagner (2011): "Individual Risk Attitudes: New Evidence from a Large, Representative, ExperimentallyValidated Survey," Journal of the European Economic Association, 9(3), 522-530.

Egan, Mark, Gregor Matvos, and Amit Seru (2019): “The market for financial adviser misconduct," Journal of Political Economy, 127(1), 233-295.

Ellul, Andrew, Marco Pagano, Annalisa Scognamiglio (2020): "Careers in finance," CEPR Discussion Paper DP14767.

Englmaier, Florian, and Georg Gebhardt (2016): "Social dilemmas in the laboratory and in the field," Journal of Economic Behavior and Organization, 128, 85-96.

Eufinger, Christian, and Andrej Gill (2017): "Incentive-based capital requirements," Management Science 63(12), 4101-4113.

Fischbacher, Urs (2007): "Z-Tree: Zurich toolbox for ready-made economic experiments," Experimental Economics 10(2), 171-178.

Fischbacher, Urs, Simon Gächter, and Ernst Fehr (2001): “Are people conditionally cooperative? Evidence from a public goods experiment," Economics Letters, 71(3), 397404.

Fischbacher, Urs, and Simon Gächter (2010): "Social preferences, beliefs, and the dynamics of free riding in public goods experiments," American Economic Review, 100(1), 541-556.

Friebel, Guido, Michael Kosfeld, and Gerd Thielmann (2019): “Trust the police? Self-selection of motivated agents into the German police force," American Economic Journal: Microeconomics, 11(4), 59-78.

Gambretta, Diego (2000): “Can we trust trust?," in Diego Gambretta (ed.), Trust: Making and Breaking Cooperative Relations, Blackwell Publishers, 213-237.

Gennaioli, Nicola, Andrei Shleifer, and Robert Vishny (2015): “Money doctors," Journal of Finance 70(1), 91-114.

Gneezy, Uri (2005): "Deception: The role of consequences," American Economic Review, 95(1), 384-394.

Gregg, Paul, Paul A. Grout, Anita Ratcliffe, Sarah Smith, and Frank Windmeijer (2011): "How important is pro-social behavior in the delivery of public services?" Journal of Public Economics, 95(7-8), 758-766.

Greiner, Ben (2015): "Subject pool recruitment procedures: Organizing experiments with ORSEE," Journal of the Economic Science Association, 1(1), 114-125.

Griffin, John, and Gonzalo Maturana (2016): "Who facilitated misreporting in securitized loans?," Review of Financial Studies, 29(2), 384-419. 
Guiso, Luigi, Paola Sapienza, and Luigi Zingales (2008): “Trusting the stock market,” Journal of Finance, 63(6), 2557-2600.

Hanna, Rema, and Shing-Yi Wang (2017): "Dishonesty and selection into public service: Evidence from India," American Economic Journal: Economic Policy, 9(3), 262-290.

Heinz, Matthias, and Heiner Schumacher (2017): "Signaling cooperation," European Economic Review, 98, 199-216.

Huck, Steffen, Gabriele Lünser, and Jean-Robert Tyran (2016): "Price competition and reputation in markets for experience goods: an experimental study," RAND Journal of Economics, 47(1), 99-117.

Karlan, Dean (2005): "Using experimental economics to measure social capital and predict financial decisions," American Economic Review, 95(5), 1688-1699.

List, John, Azeem Shaikh, and Yang Xu (2019): "Multiple hypothesis testing in experimental economics", Experimental Economics, 22, 773-793.

Mullainathan, Sendhil, Markus Noeth, and Antoinette Schoar (2012): “The market for financial advice: An audit study," NBER Working Paper No. 17929.

Philippon, Thomas, and Ariell Reshef (2012): "Wages and human capital in the U.S. finance industry: 1909 - 2006," Quarterly Journal of Economics, 127(4), 1551-1609.

Piskorski, Tomasy, Amit Seru, and James Witkin (2015): “Asset quality misrepresentation by financial intermediaries: Evidence from the RMBS market," Journal of Finance, 70, 2635 2678.

Rahwan, Zoe, Erez Yoeli, and Barbara Fasolo (2019): "Heterogeneity in banker culture and its influence on dishonesty," Nature, 575, 345-349.

Ronen, Simcha (1994): “An underlying structure of motivational need taxonomies: a crosscultural confirmation," in: Harry C. Triandis, Marvin D. Dunnette, and Leaetta M. Hough (Eds.): Handbook of industrial and organizational psychology Vol. 4 (2nd edition), 241269. Palo Alto: Consulting Psychologists Press.

Rustagi, Devesh, Stefanie Engel, and Michael Kosfeld (2010): “Conditional cooperation and costly monitoring explain success in forest commons management," Science 330, 961-965.

Sapienza, Paola, and Luigi Zingales (2012): “A trust crisis," International Review of Finance, $12(2), 123-131$.

Serra, Daniela, Pieter Serneels, and Abigail Barr (2011): "Intrinsic motivations and the nonprofit health sector: Evidence from Ethiopia," Personality and Individual Differences, 51(3), 309-314.

Villeval, Marie Claire (2014): "Professional identity can increase dishonesty," Nature, 516, 48- 
49.

Vischer, Thomas, Thomas Dohmen, Armin Falk, David Huffman, Jürgen Schupp, Uwe Sunde and Gert G. Wagner (2013): "Validating an ultra-short survey measure of patience," Economic Letters, 120(2), 142-145.

Zingales, Luigi (2015): “Does finance benefit society?,” Journal of Finance, 70(4), 1327-1363. 


\title{
Trustworthiness in the Financial Industry
}

\author{
Andrej Gill1 ${ }^{1}$, Matthias Heinz ${ }^{2}$, \\ Heiner Schumacher ${ }^{3}$, and Matthias Sutter ${ }^{4}$
}

Online Appendix

\begin{abstract}
Content
Online Appendix I: Tables for Supplementary Analyses (pp. 2-9)

Online Appendix II: Privacy Protection (pp. 10-11)
\end{abstract}

Online Appendix III: Experimental Instructions Wave 2013 (pp. 12-38)

Online Appendix IV: Interview Guide Wave 2020 (pp. 39-40)

Online Appendix V: Cooperation and Professional Preferences: Experimental Instructions (pp. 41-44)

\footnotetext{
${ }^{1}$ University of Mainz. Phone: +49 613139 22979; Email: gill@uni-mainz.de.

${ }^{2}$ University of Cologne, ECONtribute, Max Planck Institute for Research on Collective Goods, Bonn, and CEPR. Phone: +49 221479 7263; Email: heinz@wiso.uni-koeln.de.

${ }^{3}$ KU Leuven. Phone: +32 16374 579; Email: heiner.schumacher@kuleuven.be.

${ }^{4}$ Corresponding author. Max Planck Institute for Research on Collective Goods, Bonn, University of Cologne, ECONtribute, IZA Bonn, CESifo Munich and University of Innsbruck. Phone: +49 228 91416 150; Email: matthias.sutter@coll.mpg.de.
} 
Online Appendix I: Tables for Supplementary Analyses

Table A: Regression results, using amount sent as dependent variable

\begin{tabular}{lcc|cc}
\hline \hline & \multicolumn{2}{c}{ Panel A } & \multicolumn{2}{c}{ Panel B } \\
Specifications & $(1 \mathrm{a})$ & $(2 \mathrm{a})$ & $(1 \mathrm{~b})$ & $(2 \mathrm{~b})$ \\
\hline Constant & $2.960^{* * *}$ & $3.256^{*}$ & $3.322^{* * *}$ & 3.228 \\
& $(0.504)$ & $(1.926)$ & $(0.243)$ & $(1.994)$ \\
Finance interest & 0.025 & -0.021 & & \\
& $(0.094)$ & $(0.102)$ & & \\
Finance job & & & -0.415 & -0.502 \\
& & & $(0.433)$ & $(0.438)$ \\
\hline Subject pool & & & & \\
All subjects Wave 2013 & Yes & Yes & No & No \\
All subjects Wave 2020 & No & No & Yes & Yes \\
\hline Controls & No & Yes & No & Yes \\
$\mathrm{R}^{2}$ & 0.000 & 0.008 & 0.004 & 0.014 \\
Sample size & 265 & 265 & 221 & 221 \\
\hline \hline
\end{tabular}

Notes: Modified version of our baseline regressions from Table 1. Here we use the amount sent as first mover in the trust game as dependent variable. Robust standard errors are in parenthesis. ${ }^{*} \mathrm{p}<0.1, * * \mathrm{p}<0.05, * * * \mathrm{p}<0.01$.

Table B: Regression results, using a Tobit model instead of OLS

\begin{tabular}{lcc}
\hline \hline Specifications & $(1)$ & $(2)$ \\
\hline Constant & $\begin{array}{c}0.304^{* * *} \\
(0.039)\end{array}$ & $\begin{array}{c}-0.112 \\
(0.140)\end{array}$ \\
Finance interest & $-0.025^{* * *}$ & $-0.016^{* *}$ \\
& $(0.007)$ & $(0.008)$ \\
\hline Subject pool & & \\
All subjects Wave 2013 & Yes & Yes \\
All subjects Wave 2020 & No & No \\
\hline Controls & No & Yes \\
Pseudo R & 0.089 & 0.200 \\
Sample size & 265 & 265 \\
\hline \hline
\end{tabular}

Notes: Modified version of our baseline regressions for finance interest (from Table 1, Panel A). The dependent variable is the mean share returned as second mover in the trust game. Here, we use a Tobit model instead of OLS. Robust standard errors are in parenthesis. ${ }^{*} \mathrm{p}<0.1,{ }^{* *} \mathrm{p}<0.05, * * * \mathrm{p}<0.01$. 
Table C: Regression results, using six dummies for finance interest instead of the finance interest variable as independent variable

\begin{tabular}{lc}
\hline \hline Constant & $0.297^{* * *}$ \\
& $(0.053)$ \\
Finance interest $=7$ & $-0.131^{* *}$ \\
& $(0.055)$ \\
Finance interest $=6$ & $-0.097^{*}$ \\
& $(0.058)$ \\
Finance interest $=5$ & -0.053 \\
& $(0.063)$ \\
Finance interest $=4$ & -0.070 \\
& $(0.062)$ \\
Finance interest $=3$ & -0.049 \\
Finance interest $=2$ & $(0.059)$ \\
& -0.078 \\
\hline Controls & $(0.066)$ \\
Pseudo R & No \\
Sample size & 0.048 \\
\hline \hline
\end{tabular}

Notes: Modified version of our baseline regressions for finance interest (from Table 1, Panel A). The dependent variable is the mean share returned as second mover in the trust game. Here, we use six dummies for the different finance interest scores (one dummy for each score, taking as benchmark "Finance interest $=1$ ") instead of the finance interest variable in the baseline regression. Finance interest $=1$ is omitted and serves as the baseline. Robust standard errors are in parenthesis. ${ }^{*} \mathrm{p}<0.1,{ }^{* *} \mathrm{p}<0.05,{ }^{* * *} \mathrm{p}<0.01$. 
Table D: Regression results, comparing subjects with finance job and non-finance job among subjects with high finance interest

\begin{tabular}{lcc}
\hline \hline Specifications & $(1)$ & $(2)$ \\
\hline Constant & $0.208^{* * *}$ & 0.054 \\
& $(0.029)$ & $(0.143)$ \\
Finance job & $-0.091^{* * *}$ & $-0.101^{* * *}$ \\
& $(0.035)$ & $(0.033)$ \\
\hline Controls & No & Yes \\
$\mathrm{R}^{2}$ & 0.083 & 0.184 \\
Sample size & 83 & 83 \\
\hline \hline
\end{tabular}

Notes: Modified version of our baseline regressions for finance job (from Table 1, Panel B). The dependent variable is the mean share returned as second mover in the trust game. Here, we focus on the subsample of subjects with high finance interest (choosing a "7" on the Likert scale). Robust standard errors are in parenthesis. $* \mathrm{p}<0.1, * * \mathrm{p}<0.05, * * * \mathrm{p}<0.01$.

Table E: Regression results, comparing the subsample of subjects with high finance interest \& finance job to those with low finance interest \& nonfinance job

\begin{tabular}{lcc}
\hline \hline Specifications & & \\
\hline Constant & $0.264^{* * *}$ & $(1)$ \\
& $(0.022)$ & 0.059 \\
High finance interest and finance job & $-0.147^{* * *}$ & $-0.126^{* * *}$ \\
& $(0.029)$ & $(0.037)$ \\
\hline Controls & & No \\
$\mathrm{R}^{2}$ & 0.205 & 0.230 \\
Sample size & 98 & 98 \\
\hline \hline
\end{tabular}

Notes: Modified version of our baseline regressions from Table 1. The dependent variable is the mean share returned as second mover in the trust game. Here, we focus on two subsamples of subjects: i) subjects with high finance interest and finance job; ii) subjects with low finance interest and non-finance job. High finance interest and finance job is a dummy set to one for subjects with high finance interest (in Wave 2013) and a finance job (in Wave 2020). Robust standard errors are in parenthesis. $* \mathrm{p}<0.1, * * \mathrm{p}<0.05, * * * \mathrm{p}<0.01$. 


\section{Table F: Regression results, excluding subjects who changed their field of study}

\begin{tabular}{lcc}
\hline \hline Specifications & $(1)$ & $(2)$ \\
\hline Constant & $0.230^{* * *}$ & -0.118 \\
& $(0.015)$ & $(0.104)$ \\
Finance job & $-0.080^{* * *}$ & $-0.075^{* * *}$ \\
& $(0.024)$ & $(0.024)$ \\
\hline Controls & No & Yes \\
$\mathrm{R}^{2}$ & 0.052 & 0.121 \\
Sample size & 205 & 205 \\
\hline \hline
\end{tabular}

Notes: Modified version of our baseline regressions for finance job (from Table 1, Panel B). The dependent variable is the mean share returned as second mover in the trust game. Here, we exclude 16 subjects who changed their field of study between Wave 2013 and Wave 2020. Robust standard errors are in parenthesis. ${ }^{*} \mathrm{p}<0.1, * * \mathrm{p}<0.05, * * * \mathrm{p}<0.01$.

Table G: Regression results, classifying subjects who switched their job based on the second employer

\begin{tabular}{lcc}
\hline \hline Specifications & $(1)$ & $(2)$ \\
\hline Constant & $0.222^{* * *}$ & -0.128 \\
& $(0.014)$ & $(0.102)$ \\
Finance job & $-0.062^{* * *}$ & $-0.061^{* * *}$ \\
& $(0.023)$ & $(0.024)$ \\
\hline Controls & No & Yes \\
$\mathrm{R}^{2}$ & 0.031 & 0.108 \\
Sample size & 221 & 221 \\
\hline \hline
\end{tabular}

Notes: Modified version of our baseline regressions for finance job (from Table 1, Panel B). The dependent variable is the mean share returned as second mover in the trust game. For subjects, who switched their first employer after graduation between 2013 and 2020, we classified the finance job dummy based on the second employer. Robust standard errors are in parenthesis. ${ }^{*} \mathrm{p}<0.1,{ }^{* *} \mathrm{p}<0.05, * * * \mathrm{p}<0.01$. 
Table H: Distribution over industries in which subjects found their first permanent job after graduation

Sector (NACE code)

Share of subjects

Finance (K64, K65, K66)

$33.9 \%$

Consulting (M70)

$12.2 \%$

Audit (M69)

$7.7 \%$

Education (P85)

$5.4 \%$

Retail (G47)

$3.6 \%$

Food products (C10)

$3.2 \%$

Motor vehicles (C29)

$2.7 \%$

IT (J62)

$2.3 \%$

Employment Activities (N78)

$1.8 \%$

Membership organizations (e.g. parties) (S94)

$1.8 \%$

Information Services (J63)

$1.8 \%$

Advertisement \& market research (M73)

$1.8 \%$

Central or Development Bank (K66)

$1.8 \%$

Scientific Research (M72)

$1.8 \%$

Logistics (H49)

$1.4 \%$

Public Administration (O84)

$1.4 \%$

Health (Q86)

$1.4 \%$

Electricity (D35)

$1.4 \%$

Other manufacturing (C32)

$1.4 \%$

Other sectors

$11.3 \%$

Notes: The table shows the different sectors in which at least three out of the 221 subjects in Wave 2020 found their first permanent job after graduating. Column 1 provides a generic term for each sector and the respective two-digit NACE code. Column 2 shows the share of subjects who had their first job in the corresponding sector. 
Table I: Regression results, controlling for other large industries in which subjects have their first permanent job

\begin{tabular}{lcc}
\hline \hline Specifications & $(1)$ & $(2)$ \\
\hline Constant & $0.224^{* * *}$ & -0.128 \\
& $(0.017)$ & $(0.102)$ \\
Finance job & $-0.076^{* * *}$ & $-0.072 * * *$ \\
& $(0.025)$ & $(0.026)$ \\
Consulting job & 0.011 & 0.008 \\
& $(0.034)$ & $(0.036)$ \\
Audit job & 0.006 & 0.016 \\
& $(0.040)$ & $(0.033)$ \\
\hline \multirow{2}{*}{ Controls } & No & Yes \\
$\mathrm{R}^{2}$ & 0.050 & 0.124 \\
Sample size & 221 & 221 \\
\hline \hline
\end{tabular}

Notes: Modified version of our baseline regressions for finance job (from Table 1, Panel B). The dependent variable is the mean share returned as second mover in the trust game. Here, we include additional dummies in the regression for the other sectors in which a significant number of subjects found their first permanent job. "Consulting job" is the NACE code for the sector "Activities of head offices; management consultancy activities" (27 subjects), "Audit" for the sector "Legal and accounting activities" (17 subjects). Robust standard errors are in parenthesis. $* \mathrm{p}<0.1, * * \mathrm{p}<0.05, * * * \mathrm{p}<0.01$. 
Table J: Estimated probability that a subject has the first permanent job in the financial industry (probit model)

\begin{tabular}{lc}
\hline \hline Constant & $-2.347^{* *}$ \\
& $(1.032)$ \\
Finance interest & $0.244^{* * *}$ \\
& $(0.064)$ \\
Finance pre-graduation experience & $0.496^{* *}$ \\
& $(0.202)$ \\
Age & 0.036 \\
& $(0.040)$ \\
Female & -0.098 \\
& $(0.197)$ \\
Ravens score & -0.046 \\
& $(0.043)$ \\
\hline Pseudo ${ }^{2}$ & 0.127 \\
Sample size & 221 \\
\hline \hline
\end{tabular}

Notes: Probit regression. The dependent variable is a dummy set to one for finance job subjects. Finance pre-graduation experience is a dummy set to one if a subject has any experience in the financial industry before graduation. Robust standard errors are in parenthesis. ${ }^{*} \mathrm{p}<0.1, * * \mathrm{p}<0.05, * * * \mathrm{p}<0.01$. 
Table K: Regression results, including subjects who dropped out in Wave 2020, simulating their first permanent job after graduation

\begin{tabular}{lcc}
\hline \hline & Size coefficient & P-value coefficient \\
\hline $\begin{array}{l}\text { Baseline regression (Table 1, } \\
\text { Panel B, column [2b]) }\end{array}$ & -0.075 & 0.001 \\
\hline Scenario 1 (cut-off: 0\%) & -0.061 & 0.003 \\
Scenario 2 (cut-off: 10\%) & -0.065 & 0.002 \\
Scenario 3 (cut-off: 20\%) & -0.064 & 0.002 \\
Scenario 4 (cut-off: 30\%) & -0.063 & 0.004 \\
Scenario 5 (cut-off: 40\%) & -0.063 & 0.004 \\
Scenario 6 (cut-off: 50\%) & -0.073 & 0.001 \\
Scenario 7 (cut-off: 60\%) & -0.072 & 0.002 \\
Scenario 8 (cut-off: 70\%) & -0.072 & 0.002 \\
Scenario 9 (cut-off: $80 \%$ ) & -0.072 & 0.002 \\
Scenario 10 (cut-off: 90\%) & -0.072 & 0.002 \\
Scenario 11 (cut-off: $100 \%)$ & -0.072 & 0.002 \\
\hline \hline
\end{tabular}

Notes: Here, we rerun our regression for finance job (Table 1, Panel B). The dependent variable is the mean share returned as second mover in the trust game. Here we include the 35 drop-out subjects, and simulate eleven different scenarios. In each scenario, we vary the classification of drop-out subjects based on the predicted probabilities (regression from Table J). In Scenario 1, the finance job dummy is set to one for all drop-out subjects; in Scenario 2, the finance job dummy is set to one for all drop-out subjects who have a probability of $10 \%$ or higher to have the first job in the financial industry (otherwise zero); and so forth. The table shows the main coefficient of interest for each regression and the respective p-value. Number of observations in all simulations: 265. 


\section{Online Appendix II: Privacy Protection}

In order to link the two datasets Wave 2013 and Wave 2020, while also preserving subjects' anonymity throughout the process, we implemented the following procedure. After collecting the data for Wave 2020, we created four different datasets: DAT1, DAT2, DAT3, and DAT4. There is a link between DAT1 and DAT2 (i.e., they could be merged into one dataset), a link between DAT2 and DAT3, and a link between DAT3 and DAT4. There is one team (TEAM12) that worked only on the datasets DAT1 and DAT2, and another separate team (TEAM34) that worked only on datasets DAT3 and DAT4. There is no overlap between the members of TEAM12 and TEAM34. No member of the group of authors was part of TEAM34. After works on these datasets were completed, DAT2 and DAT3 were merged to a new dataset, DAT5, by an external, paid party (TEAM5). DAT5 then was used to merge DAT1 and DAT4. The team of authors only worked with the resulting dataset (DAT6).

In the following, we explain in detail the types of data that each dataset contained, and how this procedure preserves the anonymity of our subjects. A short version of these explanations was provided to our subjects in Wave 2020.

DAT1 contained the individual behavior of our subjects in the trust-game of Wave 2013 and an identification number, subject-ID1, for each subject. DAT2 contained a number of indicator variables for each subject. These were lab-session-number, start of studies, gender, secondary school, languages spoken, and professional experience prior to July 2013. DAT2 also contained the subject-ID1. Only TEAM12 worked on these datasets.

DAT3 contained the following data from Wave 2020: current employer, professional experience, the same indicator variables as DAT2. Moreover, it contained a new identification number, subject-ID2, for each subject. Subject-ID1 and subject-ID2 were different for each subject. DAT4 contained the same data as DAT3 without the indicator variables. Moreover, all employer names (firms) were replaced by industry codes (NACE) by TEAM34. DAT3 and DAT4 were created through the telephone survey in Wave 2020. Only TEAM 34 worked on these datasets.

TEAM5 was an independent external party - an IT freelancer who was paid for merging DAT2 and DAT3 to DAT5 by using the indicator variables (the contact details of the IT freelancer can be provided upon request). Importantly, TEAM5 had no access to subjects' experimental behavior (which was contained in DAT1), and no information about the purpose of our project. Moreover, TEAM5 was contractually obliged to delete all datasets related to the 
project after completing its task. The resulting dataset DAT5 only contains the connection between subject-ID1 and subject-ID2 (so it is essentially a "key").

We then merged DAT1 and DAT4 by using DAT5. The resulting dataset DAT6 is the dataset that is used by the team of authors. All analyses and conclusions follow exclusively from DAT6. All other datasets were deleted from all devices used. 


\section{Online Appendix III: Experimental Instructions Wave 2013}

We present here the original German screens in zTree and provide an English translation beneath each screen.

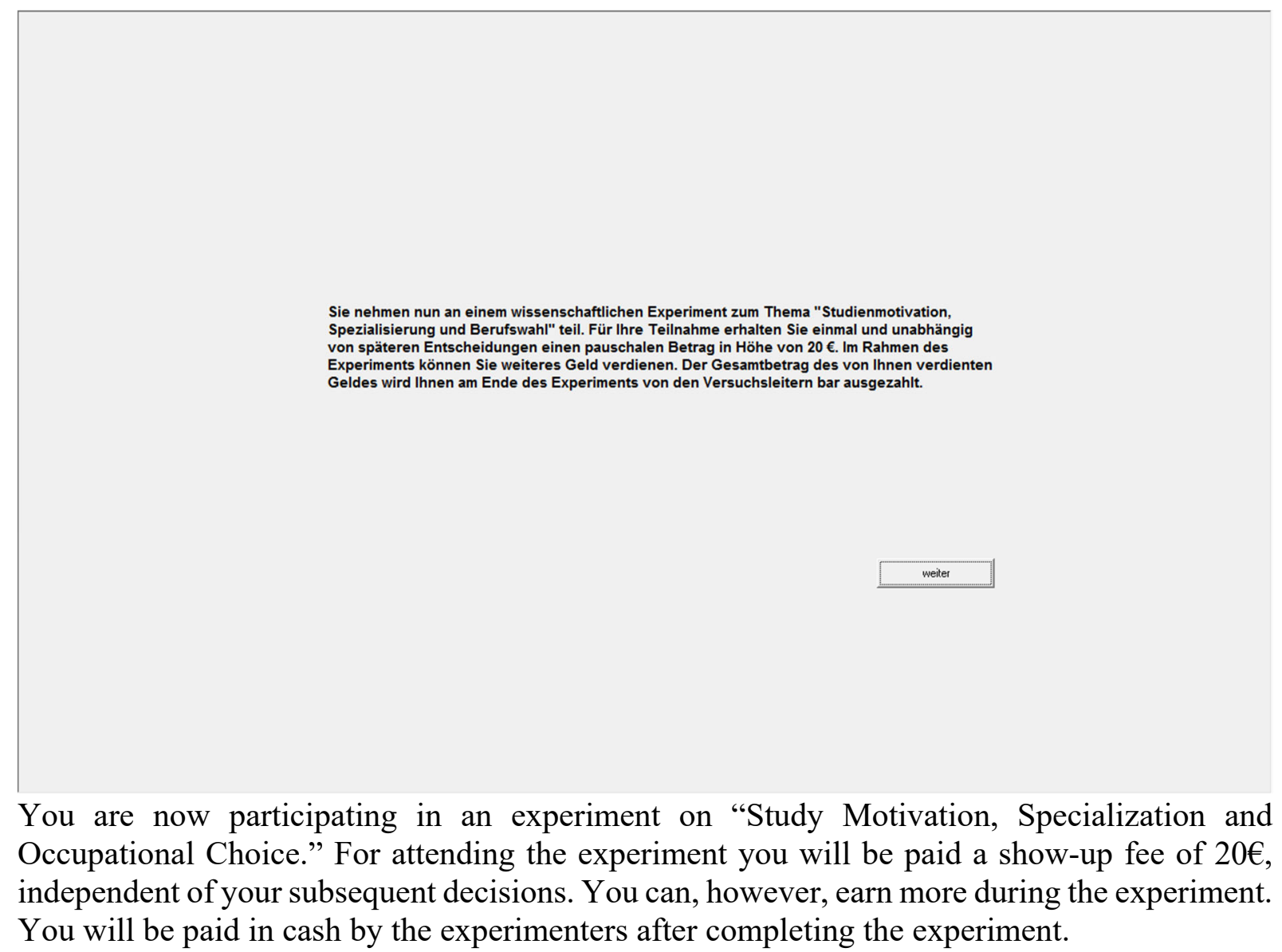


Sowohl Sie als auch alle anderen Teilnehmer treten als vollkommen anonyme Teilnehmer auf. Auch im Anschluss an das Experiment werden keinerlei Identitäten bekannt gegeben. Bitte unterhalten Sie sich während des Experiment nicht mit anderen Teilnehmern. Sollten Sie Fragen haben, heben Sie bitte die Hand. Die Versuchsleiter werden Ihnen daraufhin zu Hilfe kommen.

The interaction between you and all other participants in the experiment is absolutely anonymous. Also, after the experiment, no identities will be revealed. If you have any questions at any time, please raise your hand. The experimenters will then assist you. 
Das heutige Experiment besteht aus mehreren Teilen. Alle Teile sind unabhängig voneinander. Das heißt, Ihre Entscheidungen in einem Teil haben keinerlei Auswirkungen auf den weiteren Verlauf des Experiment.

Today's experiment consists of several parts. All parts are independent from each other. This means that your decisions in one part of the experiment will not have any effect on the subsequent parts of the experiment.

Im Folgenden finden Sie zunächst einen kurzen Fragebogen. Bitte lesen Sie sich alle Fragen sorgfältig durch und beantworten Sie diese wahrheitsgemäß.

In the following, you find a short questionnaire. Please, read all questions carefully and answer the questions truthfully. 
Die folgenden Fragen enthalten Aussagen welche sich zur Beschreibung Ihrer eigenen Person eignen können. Es gibt keine richtigen oder falschen Antworten. Bitte lassen Sie keinen Frage aus und kreuzen Sie die Antworten an, die am ehsten auf Sie zutreffen

Ich habe gerne viele Leute um mich herum.
Ich halte meine Sachen ordentlich und sauber.
Ich fühle mich anderen oft unterlegen.
Ich bin leicht zum Lachen zu bringen.
Ich finde philosophische Diskussionen langweilig.
Ich bekomme häufiger Streit mit meiner Familie und
meinen Kollegen.
Ich kann mir meine Zeit recht gut einteilen, so dass ich
meine Angelegenheiten rechtzeitig beende.
$\begin{aligned} & \text { Wenn ich unter starkem Stress stehe, fühle ich mich } \\ & \text { manchmal, als ob ich zusammenbräche. }\end{aligned}$
Mich begeistern die Motive, die ich in der Kunst und in
der Natur finde.
Manche Leute halten mich für selbstsüchtig und
selbstgefällig.

Ich versuche, alle mir übertragenen Aufgabe sehr gewissenhaft zu erledigen.

Ich fühle mich oft angespannt und nervös.

Ich bin gerne im Zentrum des Geschehens

Poesie beeindruckt mich wenig oder gar nicht

Im Hinblick auf die Absichten anderer bin ich eher zynisch und skeptisch.

Manchmal fühle ich mich völlig wertlos.

Ich habe oft das Gefühl, vor Energie überzuschäumen.

Ich bin ein fröhlicher, gutgelaunter Mensch

Manche Leute halten mich für kalt und berechnend.

Wenn ich eine Verpflichtung eingehe, so kann man sich $r \quad r \quad r \quad r$ auf mich bestimmt verlassen

Zu häufig bin ich entmutigt und will aufgeben, wenn etwas schief geht.

Wenn ich Literatur lese odere 年 Begeisterung. 


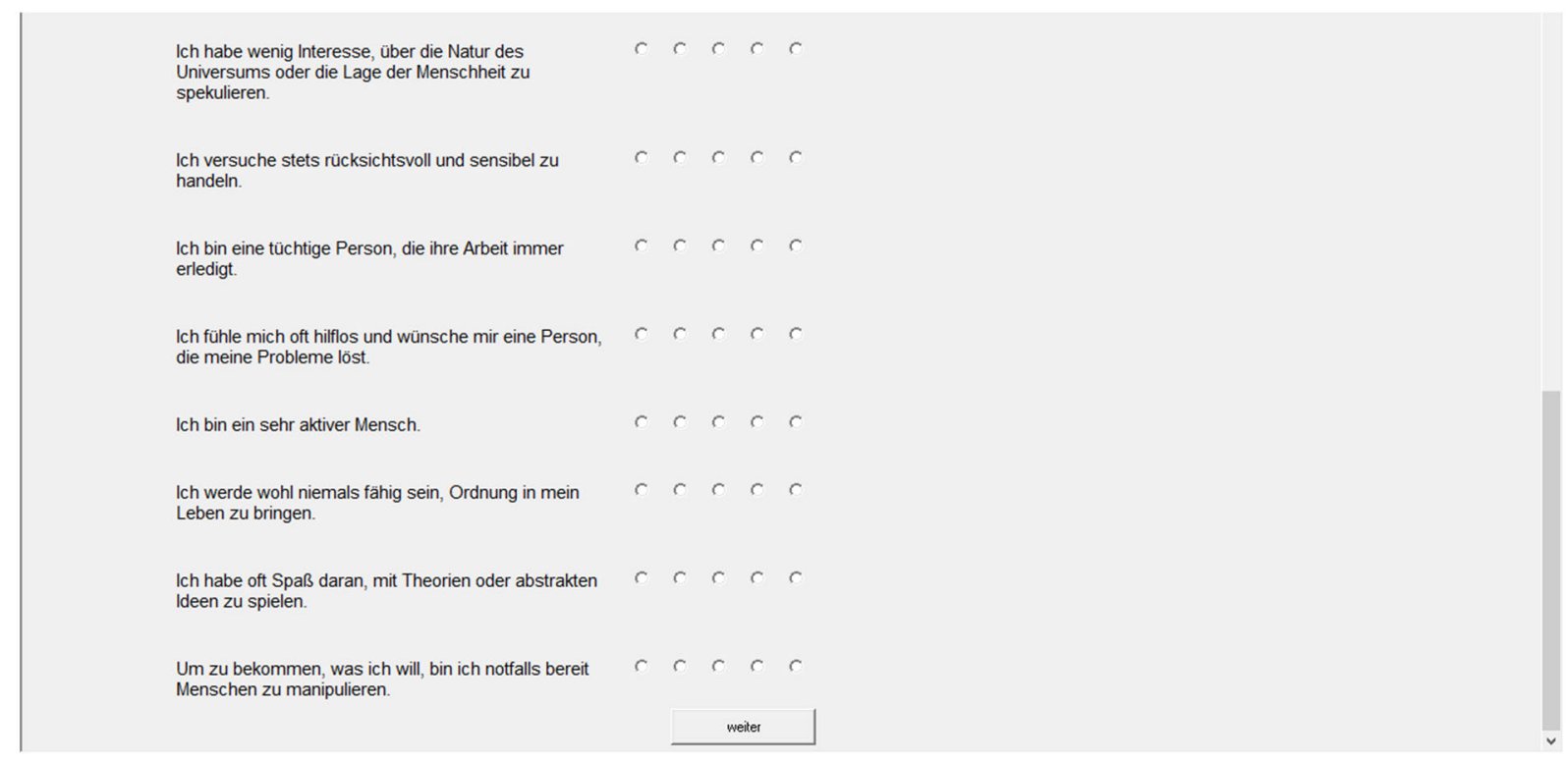

[Big-5 questions]

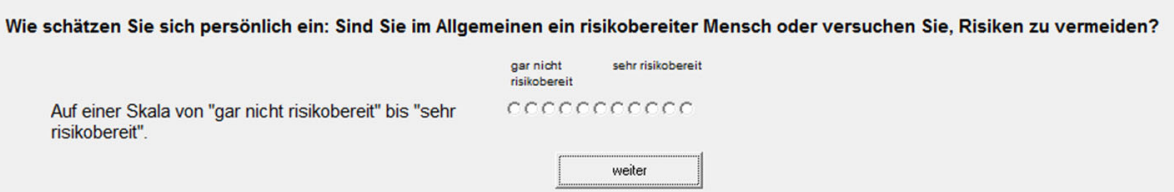

How do you see yourself: Are you generally a person who is fully prepared to take risks or do you try to avoid taking risk? On a scale from "not at all willing to take risks" to "very willing to take risks." 
Wie schätzen Sie sich persönlich ein: Sind Sie im Allgemeinen ein Mensch der ungeduldig ist, oder der immer sehr viel Geduld aufbringt?

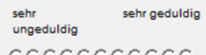

Auf einer Skala von "sehr ungeduldig" bis "sehr $\quad$ ungeduldig
geduldig".

weiter

How do you see yourself: Are you generally an impatient person, or someone who always shows great patience? On a scale from "very impatient" to "very patient." 


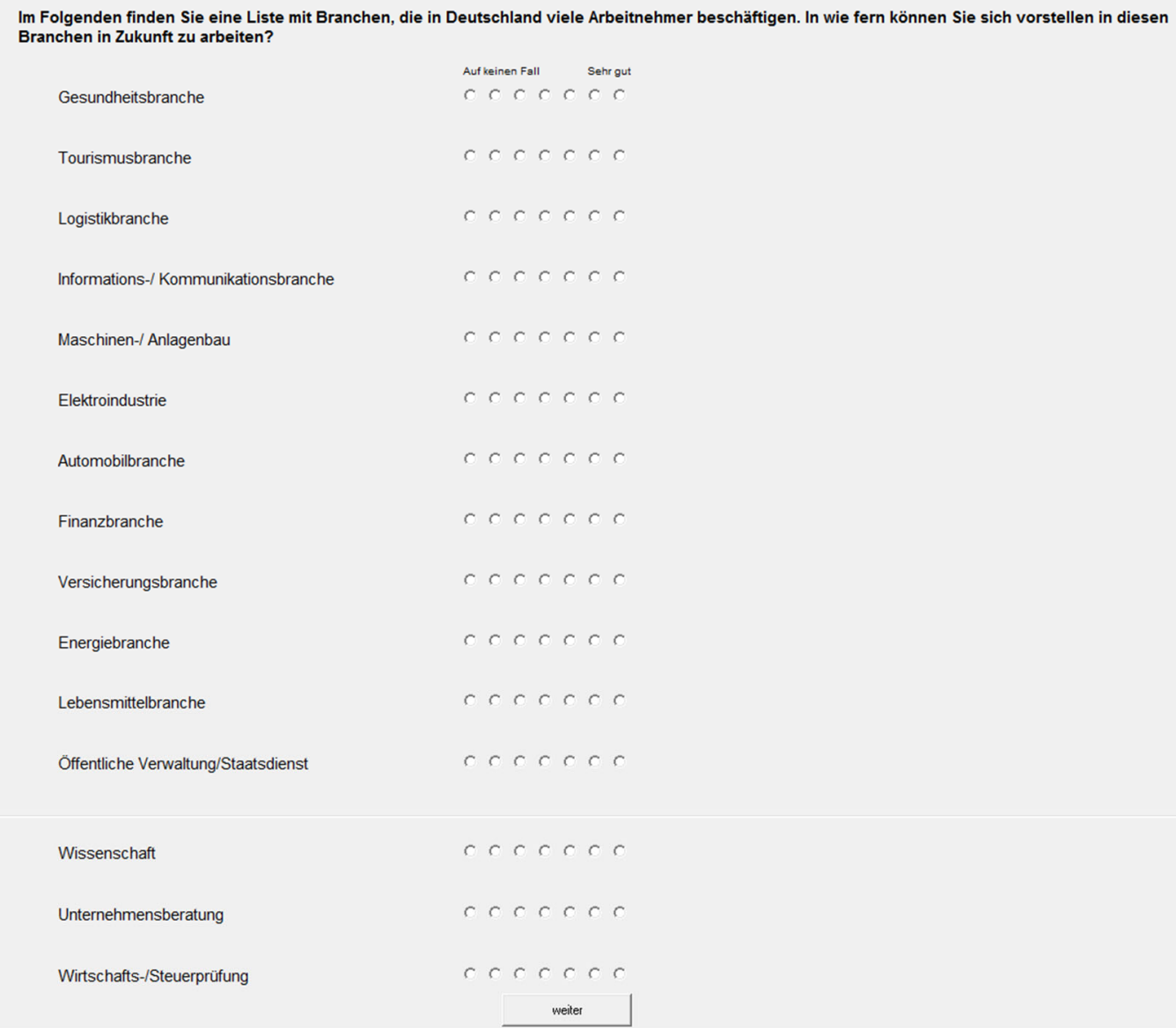

In the following, you find a list of industries that employ many people in Germany. To what extent can you imagine working in the following industries in the future (from "not at all" to "very much so")? Health, touristic, logistics, IT/communication, engineering, electronics, car manufacturing, finance, insurance, energy, retail, public service, science, consulting, auditing. 


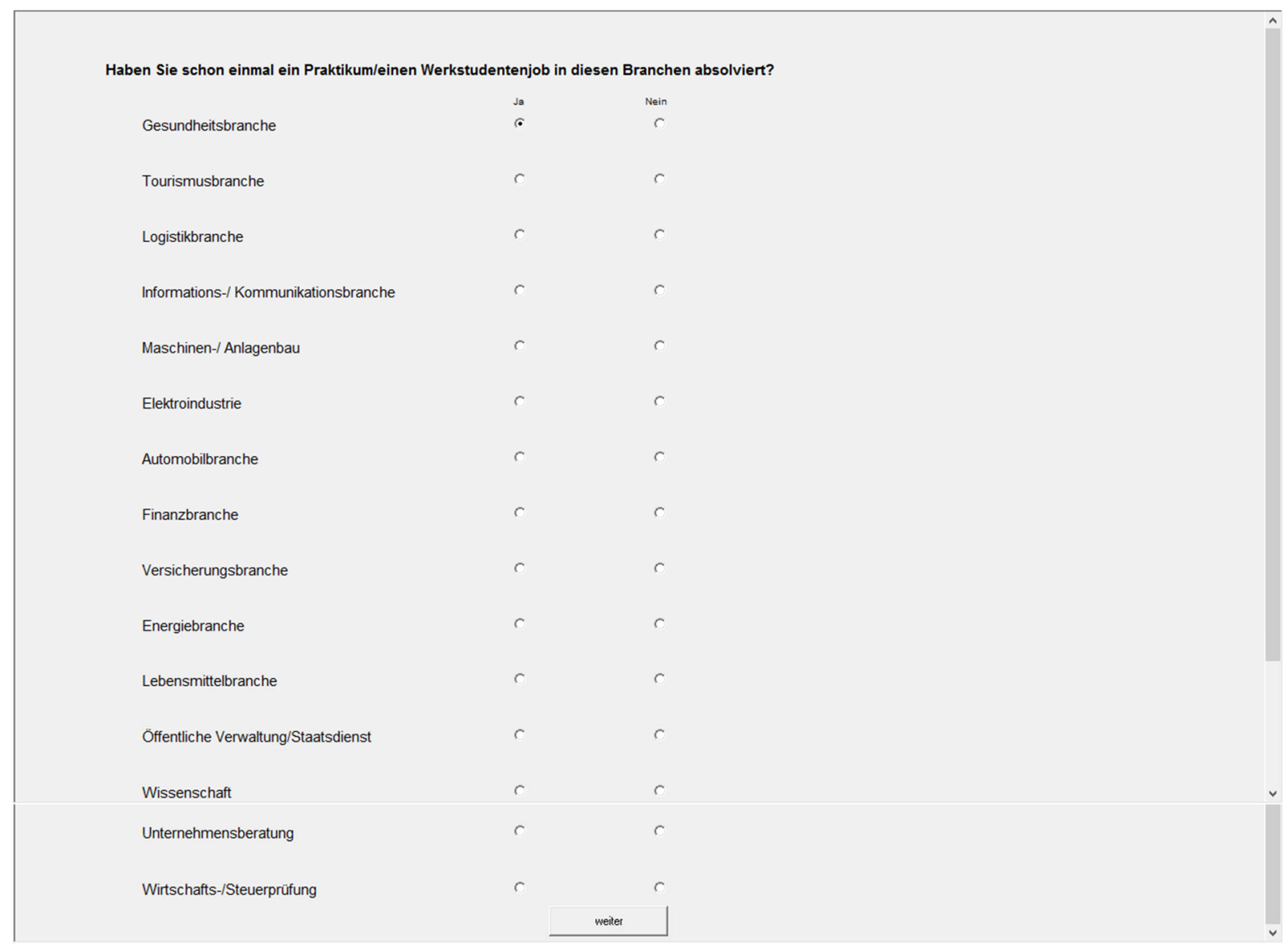

Did you complete an internship or a student job in one of these industries? Health, touristic, logistics, IT/communication, engineering, electronics, car manufacturing, finance, insurance, energy, retail, public service, science, consulting, auditing. 


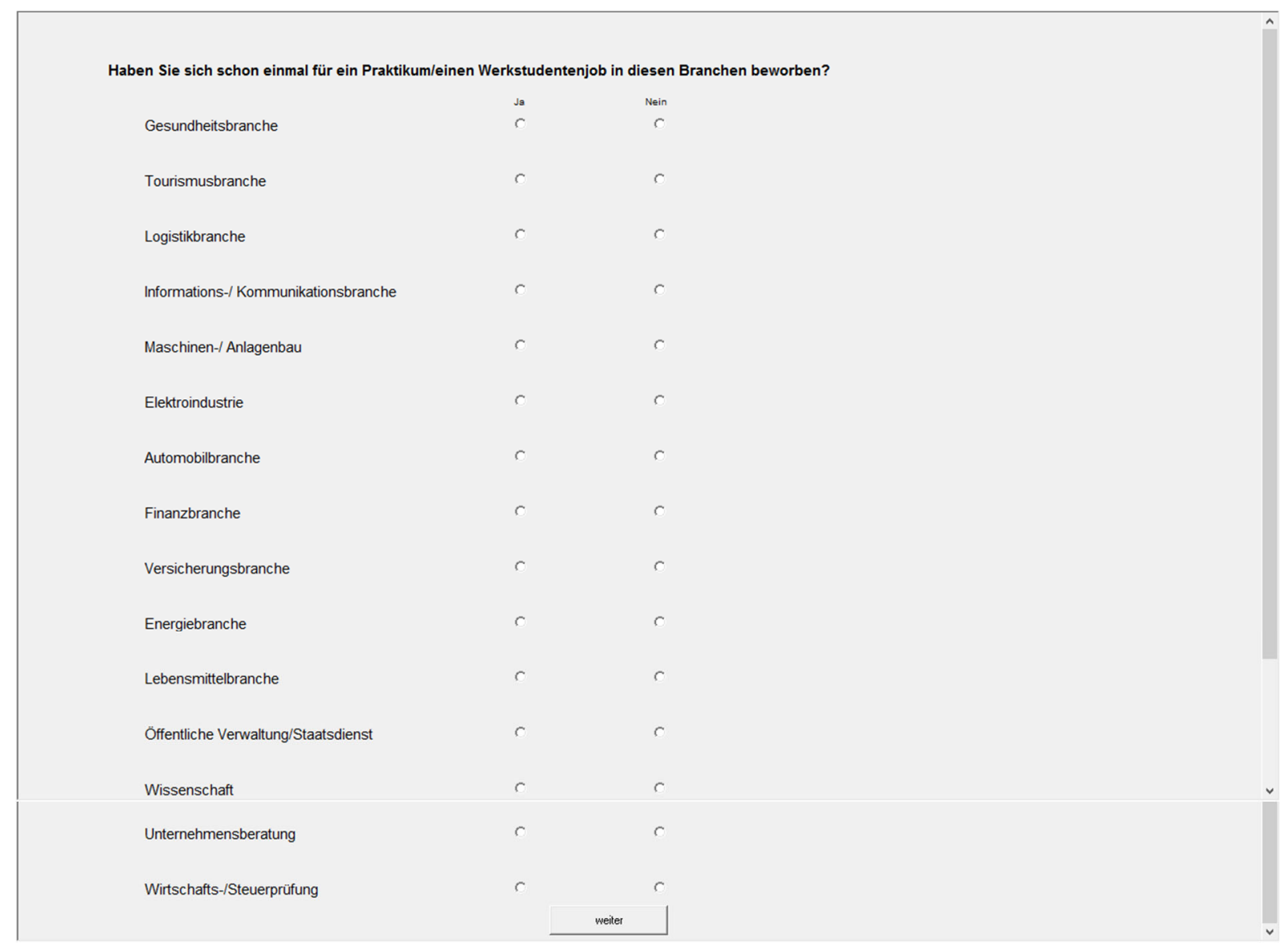

Have you ever applied for an internship or a student job in one of those industries? Health, touristic, logistics, IT/communication, engineering, electronics, car manufacturing, finance, insurance, energy, retail, public service, science, consulting, auditing. 


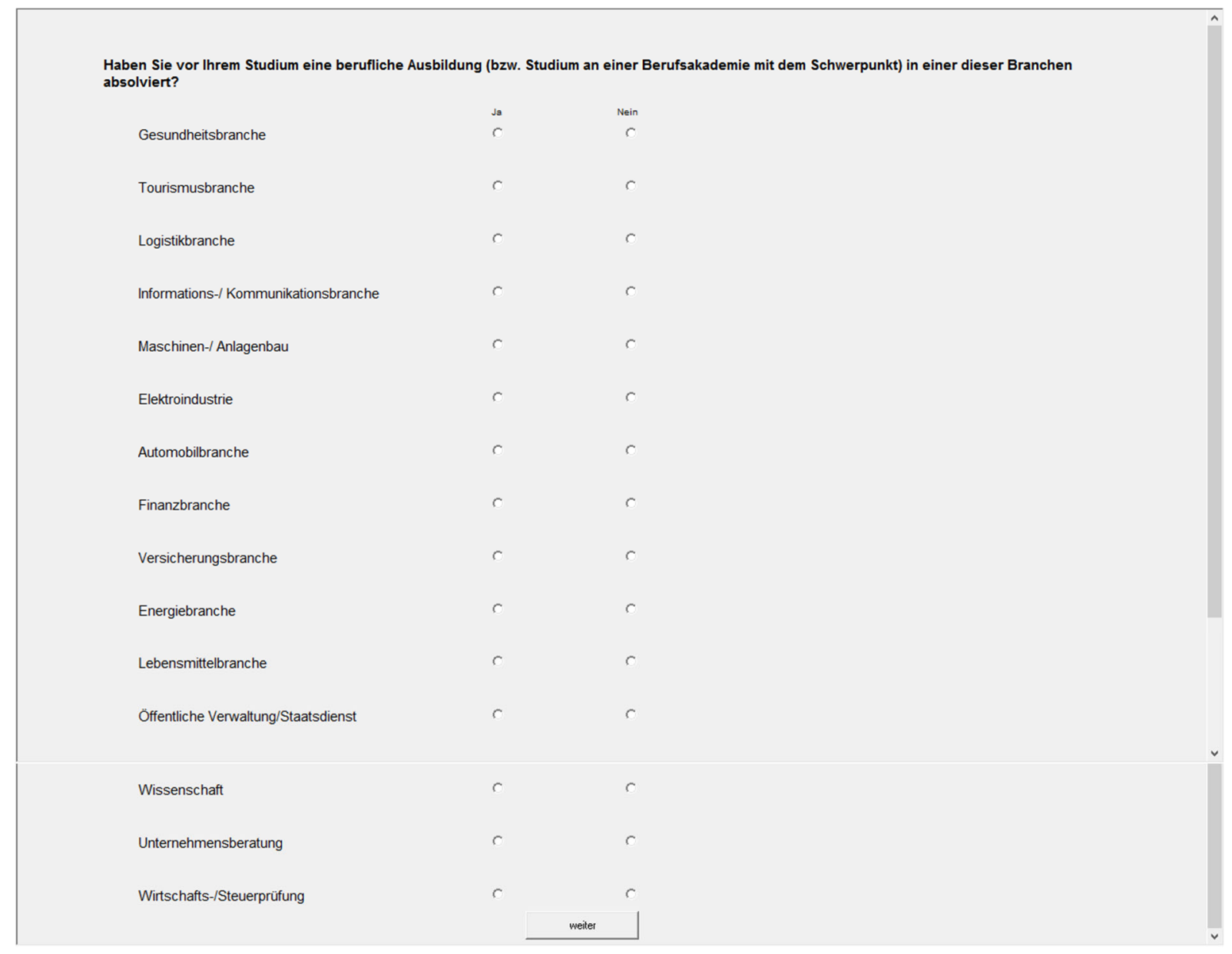

Before commencing your studies, did you complete a vocational training program (or did you study at a vocational college) in one of these industries? Health, touristic, logistics, IT/communication, engineering, electronics, car manufacturing, finance, insurance, energy, retail, public service, science, consulting, auditing. 


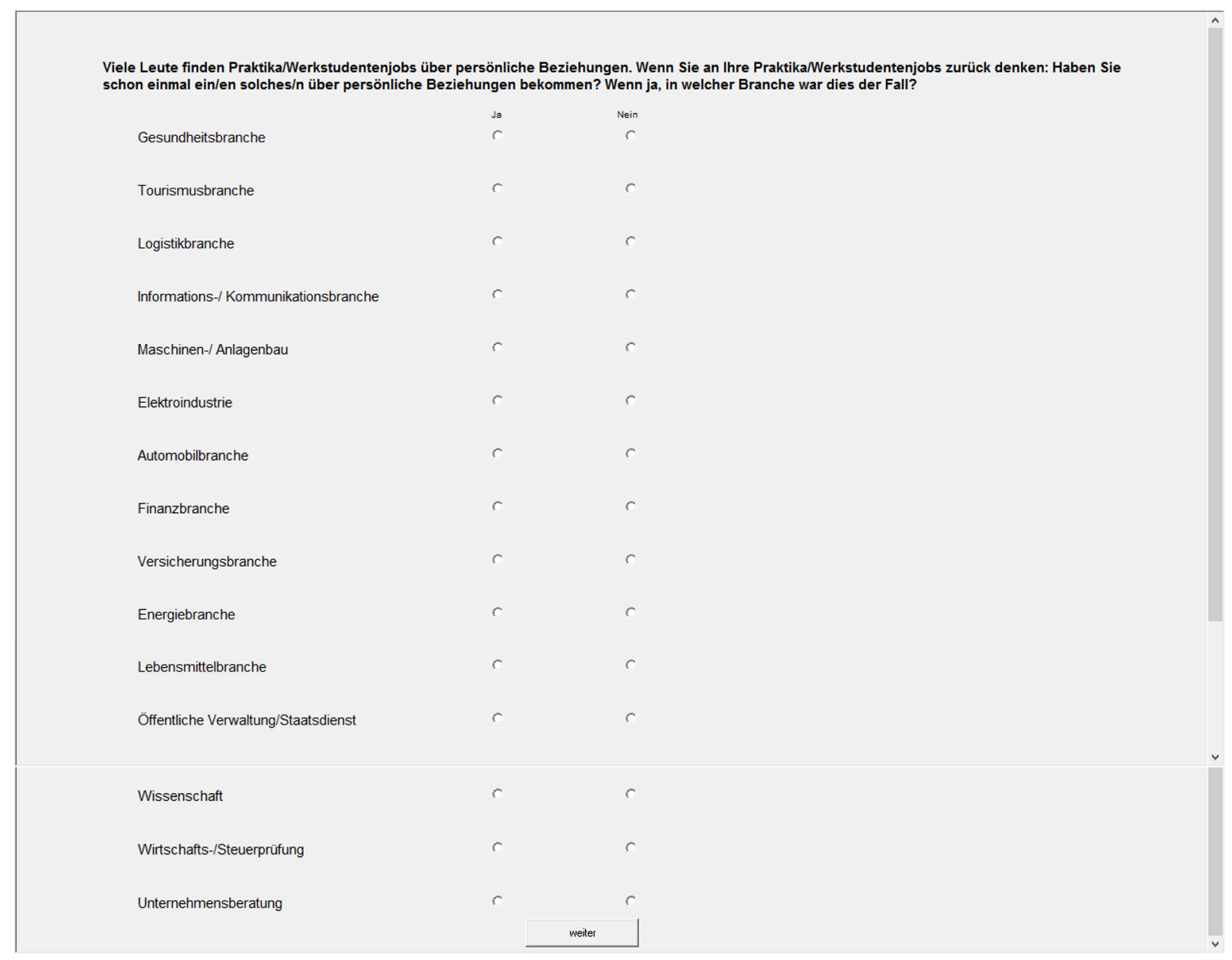

Many people find their job through personal relationships. If you think back about your internships/student jobs: Have you ever found an internship/job via personal relationships? If yes, in which industry? Health, touristic, logistics, IT/communication, engineering, electronics, car manufacturing, finance, insurance, energy, retail, public service, science, consulting, auditing. 


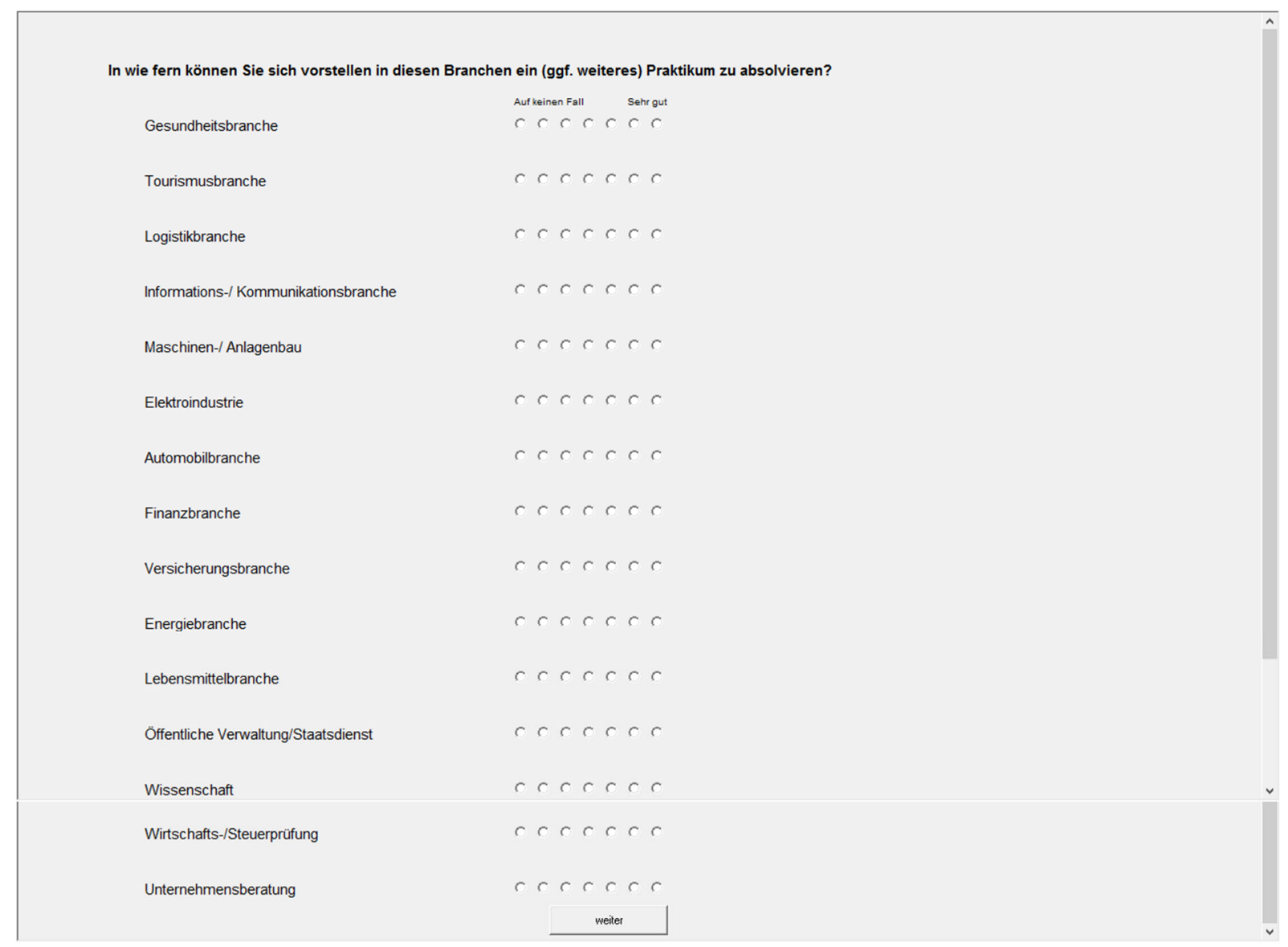

To what extent can you imagine completing (another) internship in the following industries in the future? Health, touristic, logistics, IT/communication, engineering, electronics, car manufacturing, finance, insurance, energy, retail, public service, science, consulting, auditing. 


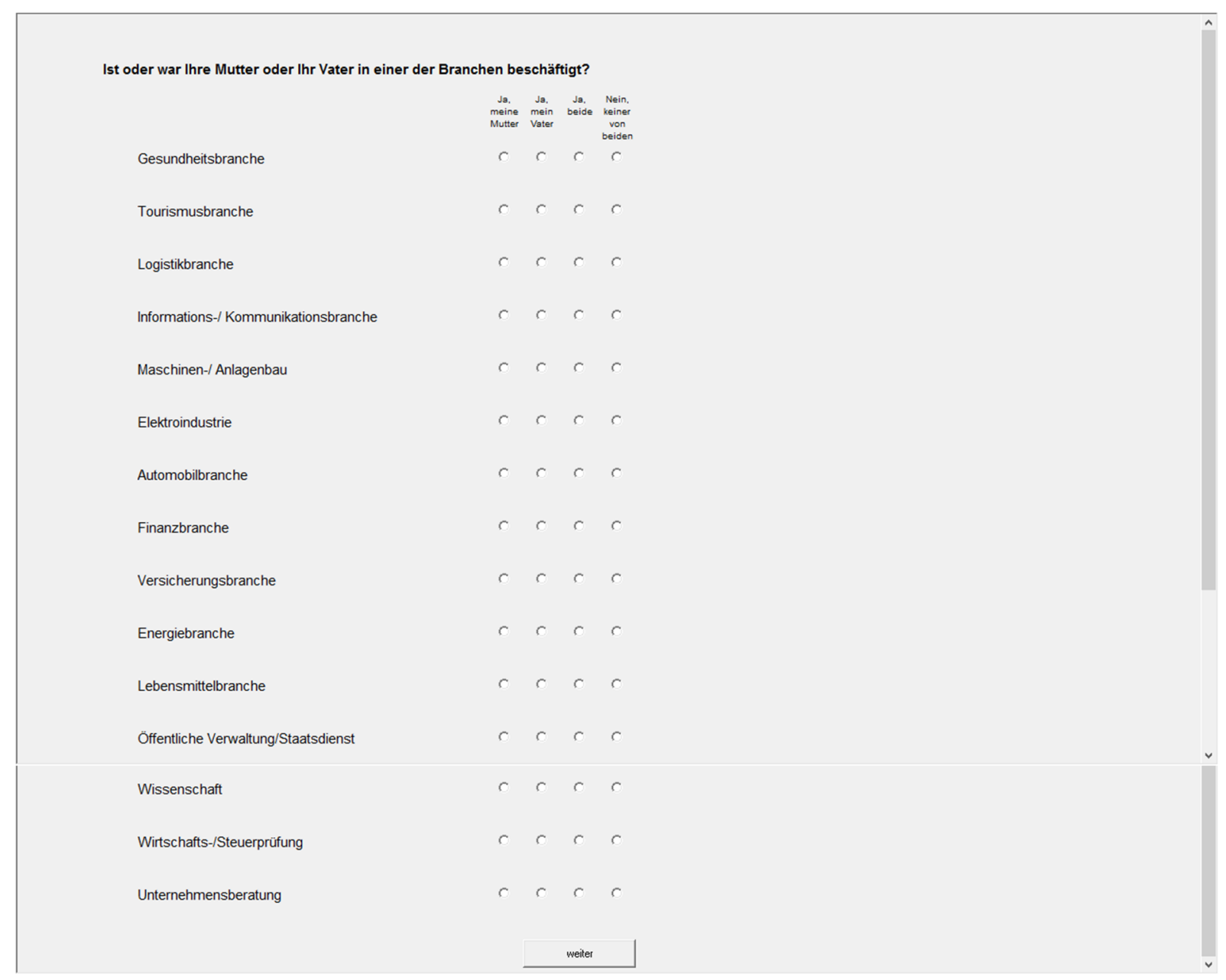

Does/has your mother or your father work/ed in these industries? Health, touristic, logistics, IT/communication, engineering, electronics, car manufacturing, finance, insurance, energy, retail, public service, science, consulting, auditing. 
Im folgenden finden Sie eine Liste mit Bereichen, in denen viele Leute mit einem abgeschlossenen Studium der Wirtschaftswissenschaften arbeiten. In wie fern können Sie sich vorstellen in diesen Bereiche zu arbeiten?

Personal

Auf keinen Fall Sehr gut

Werbung

$\cos c c c$

Vertrieb

$\cos c r c$

Forschung \& Entwicklung

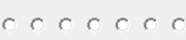

Interne Kontrolle

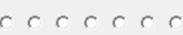

Unternehmensfinanzierung

$\operatorname{coc} c e$

In the following, you find a list of corporate divisions where many people work after graduating in economics. To what extent can you imagine working in these divisions? Personnel, advertising, sales, research and development, internal control, corporate finance. 
Im folgenden finden Sie eine Liste mit den 10 Unternehmen, die im DAX die höchste Index-Gewichtung haben. In wie fern können Sie sich vorstellen in diesen Unternehmen zu arbeiten?

BASF

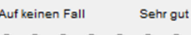

Siemens

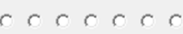

Bayer

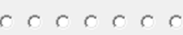

SAP

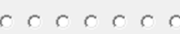

Allianz

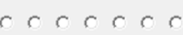

Daimler

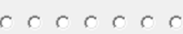

Dt. Bank

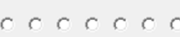

Linde

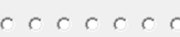

Dt. Telekom

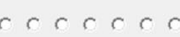

E.ON

$\cos c c c$

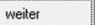

In the following, you find the list of the 10 companies with the highest weights in the DAX. To what extent can you image working in these companies (from "not at all" to "very much so")? 


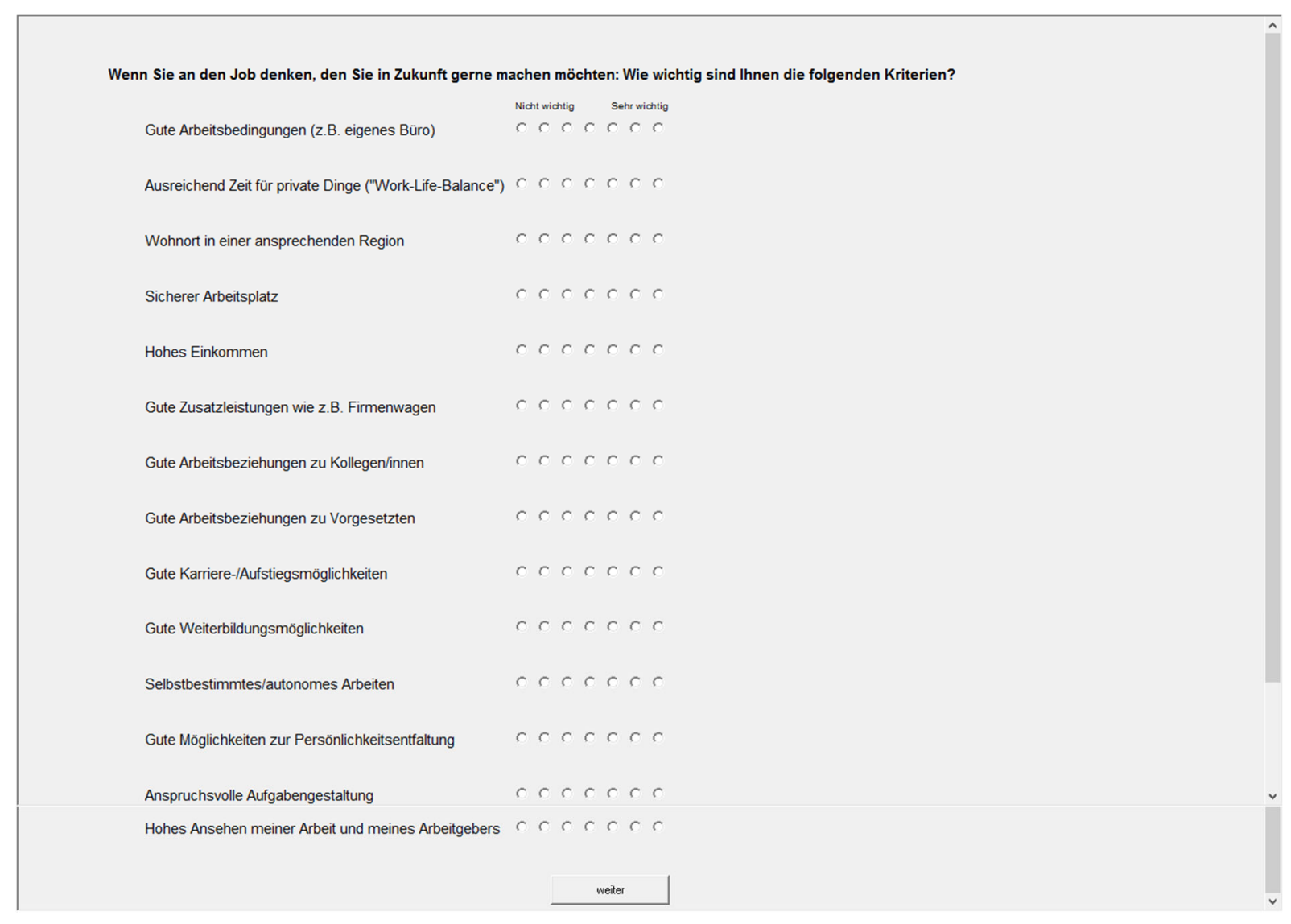

If you think about the job you would like to do in the future: Which criteria do you consider as important for you? Good working conditions (e.g., having your own office), sufficient time for private life ("work-life-balance"), place of residence in a nice region, job security, high earnings, good benefits (e.g., having a company-sponsored car), good relations to co-workers, good relations to your boss, good career opportunities, good training opportunities, selfdetermination/autonomy, good opportunities for personality developments, challenging tasks, high reputation of my work and my employer. 
Now the second part of the experiment starts: A quick test.

\author{
Instruktionen zum Test
}

Im Folgenden sehen Sie jeweils ein Muster, in dem ein Ausschnitt fehlt.
Sie haben jeweils 8 Vorschläge zur Auswahl, um den fehlenden Ausschitt zu
ergänzen.
Ihre Aufgabe besteht also darin, den Vorschlag auszuwählen, welcher das Muster am
Besten ergänzt.
Bevor der eigentliche Test beginnt, zeigen wir Innen im Folgenden zwei
Übungsmuster. Sie haben bei den beiden Übungsmustern soviel Zeit, wie Sie
möchten, um Ihre Entscheidung zu treffen.
Danach beginnt der eigentliche Test und Sie haben 12 Minuten Zeit um die restlichen
12 Muster zu lösen. Wenn Sie bei einem Muster eine Entscheidung getroffen haben,
dann kommen Sie zum nächsten Muster, und können nicht wieder zurück.
weiter

In the following, you see an image where one piece is missing. We then show you eight pieces, one of them is the missing piece.

Your job is to select the missing piece.

Before the test starts, we show you two training images. You have as much time as you want to identify the missing piece in the training image.

After this, the test starts. You have 12 minutes to solve the 12 images. If you have chosen one piece, the next one will show up and you cannot go back. 


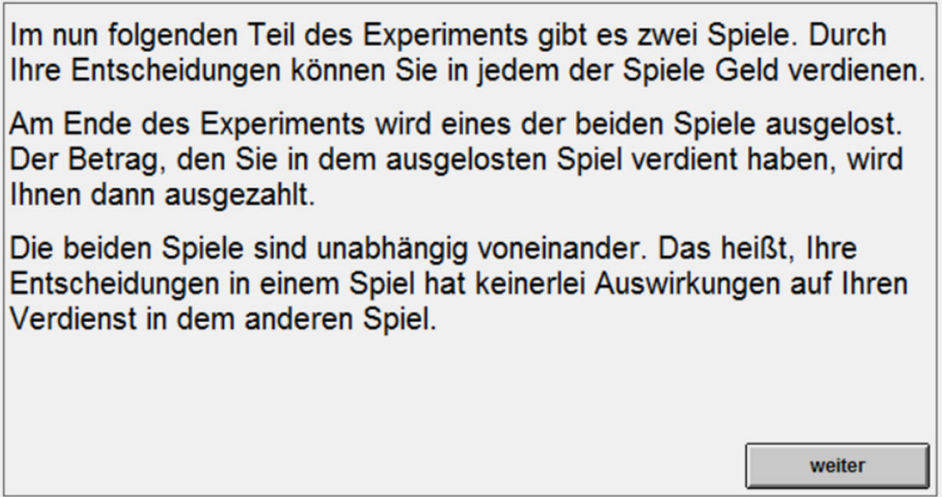

In the following part of the experiment, there are two games. Based on your decisions, you can earn money in both games.

At the end of the experiment, we will randomly select one game. The money you have earned in this particular game will be paid out to you.

Both games are independent from each other. This means that your decisions in one game have no impact on your income in the other game. 
In beiden Spielen wird Ihnen zufällig ein anderer Teilnehmer zugeordnet. Hierbei treten Sie beide vollkommen anonym auf.

Das zugrundeliegende Spiel ist in den Spielen 1 und 2 das gleiche und sieht wie folgt aus.

In both games, you are randomly matched with another participant. The interaction is completely anonymous.

The basic game structure is the same in game 1 and 2 and looks as follows. 
In dem Spiel gibt es einen Sender und einen Empfänger.

Der Sender erhält zunächst 8 Euro. Er kann daraufhin entscheiden, wie viele er von seinen 8 Euro an den Empfänger sendet. Jeder Euro, den der Sender an den Empfänger sendet, wird dabei von den Experimentatoren verdreifacht.

Das heißt: Sendet der Sender 1 Euro, erhält der Empfänger 3 Euro. Sendet der Sender 2 Euro, erhält der Empfänger 6 Euro. Sendet der Sender 3 Euro, erhält der Empfänger 9 Euro, usw.

There are two player roles in the game, sender and receiver.

The sender is endowed with 8 Euros. He decides how many of his/her 8 Euros he/she wants to send to the receiver. For each Euro that is sent, the receiver gets three Euros.

For example, if the sender sends 1 Euro, the receiver gets 3 Euros. If the sender sends 3 Euros, the receiver gets 9 Euros, and so forth. 
Der Empfänger erhält zunächst kein Geld. Nachdem der Empfänger aber Geld vom Sender empfangen hat, hat er die Möglichkeit zu entscheiden wie viel Geld er dem Sender zurücksenden möchte. Bei der Rücküberweisung wird das Geld nicht verdreifacht, d.h. der Sender erhält das Geld, was der Empfänger zurücksendet.

Die Auszahlung des Senders berechnet sich daher wie folgt: 8 Euro - gesendeter Betrag + zurückgesendeter Betrag

Die Auszahlung des Empfängers: (Gesendeter Betrag) * 3 - zurückgesendeter Betrag

Initially, the receiver has no endowment. After receiving money from the sender, he/she decides which amount he/she wants to send back. The amount sent back will not be tripled, i.e., the sender receives the amount the receiver sends back to him.

The sender's payoff is: 8 Euros - amount sent + amount sent back to the sender The receiver's payoff is: (amount sent) $* 3$ - amount sent back to the sender 


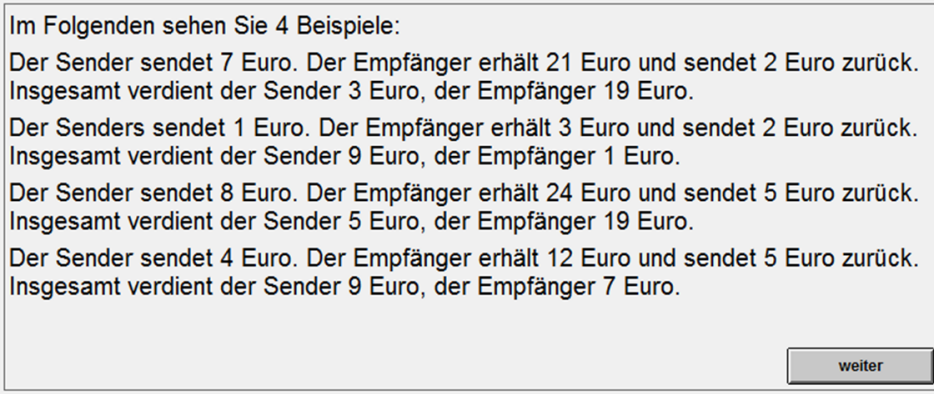

In the following, you see four examples:

The sender sends 7 Euros. The receiver gets 21 Euros and sends back 2 Euros. In total, the sender earns 3 Euros, the receiver 19 Euros.

The sender sends 1 Euro. The receiver gets 3 Euros and sends back 2 Euros. In total, the sender earns 9 Euros, the receiver 1 Euro.

The sender sends 8 Euros. The receiver gets 24 Euros and sends back 5 Euros. In total, the sender earns 5 Euros, the receiver 19 Euros.

The sender sends 4 Euros. The receiver gets 12 Euros and sends back 5 Euros. In total, the sender earns 9 Euros, the receiver 7 Euros. 
Im Folgenden spielen Sie dieses Spiel zwei Mal: Zunächst übernehmen Sie die Rolle des Senders (Spiel 1), dann des Empfängers (Spiel 2).

Beachten Sie, dass Ihnen erst am Ende mitgeteilt wird welche Entscheidungen der andere Teilnehmer getroffen hat.

In the following, you play this game two times: First as sender (game 1), and then as receiver (game 2). Note that you will be informed about the decision of your opponent just at the end of the experiment. 


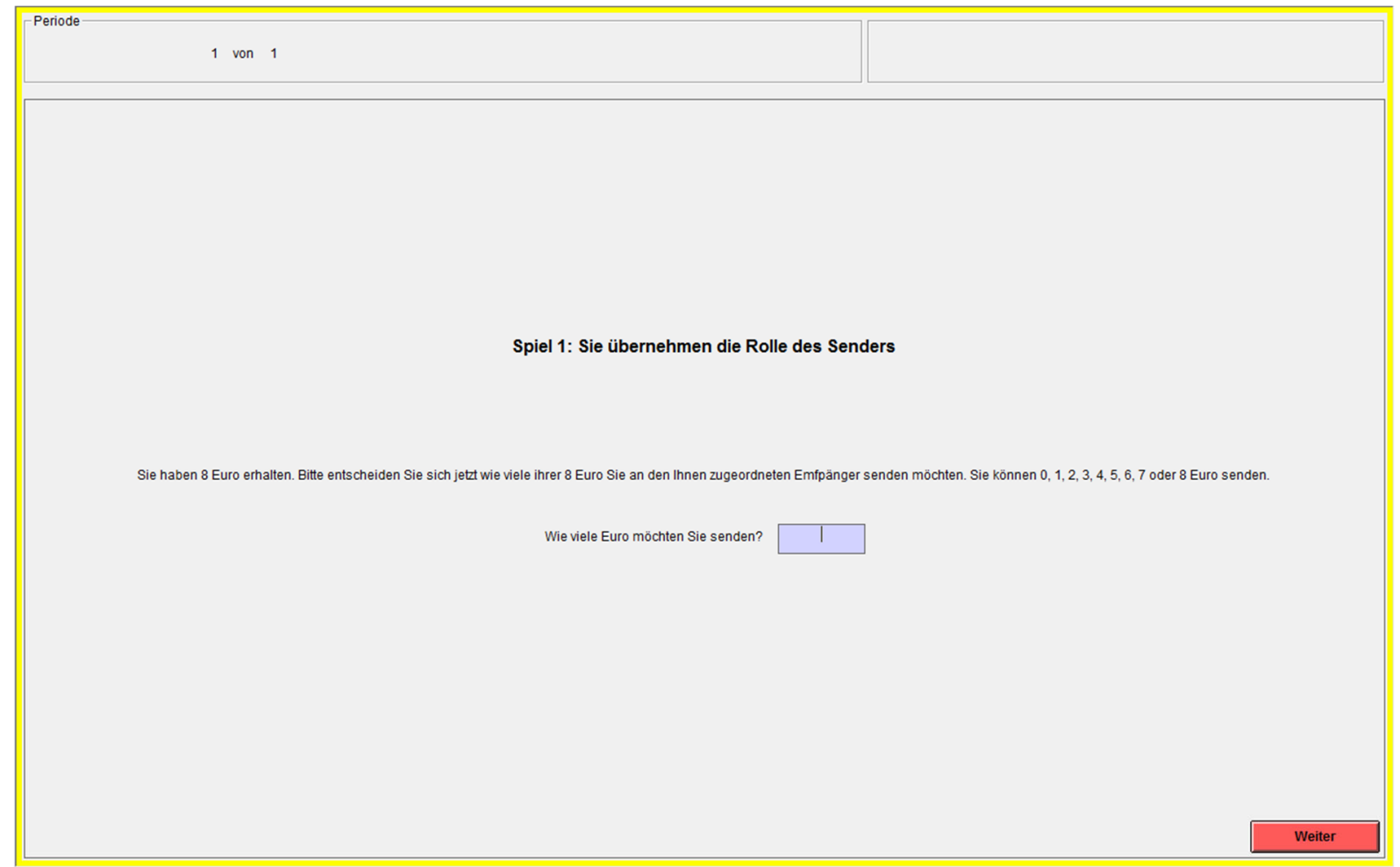

Game 1: You are the sender. You received 8 Euros. Please, decide now how many of your 8 Euros you want to send to the receiver. You can send 0, 1, 2, 3, 4, 5, 6, 7, 8 Euros. How many Euros do you want to send? 


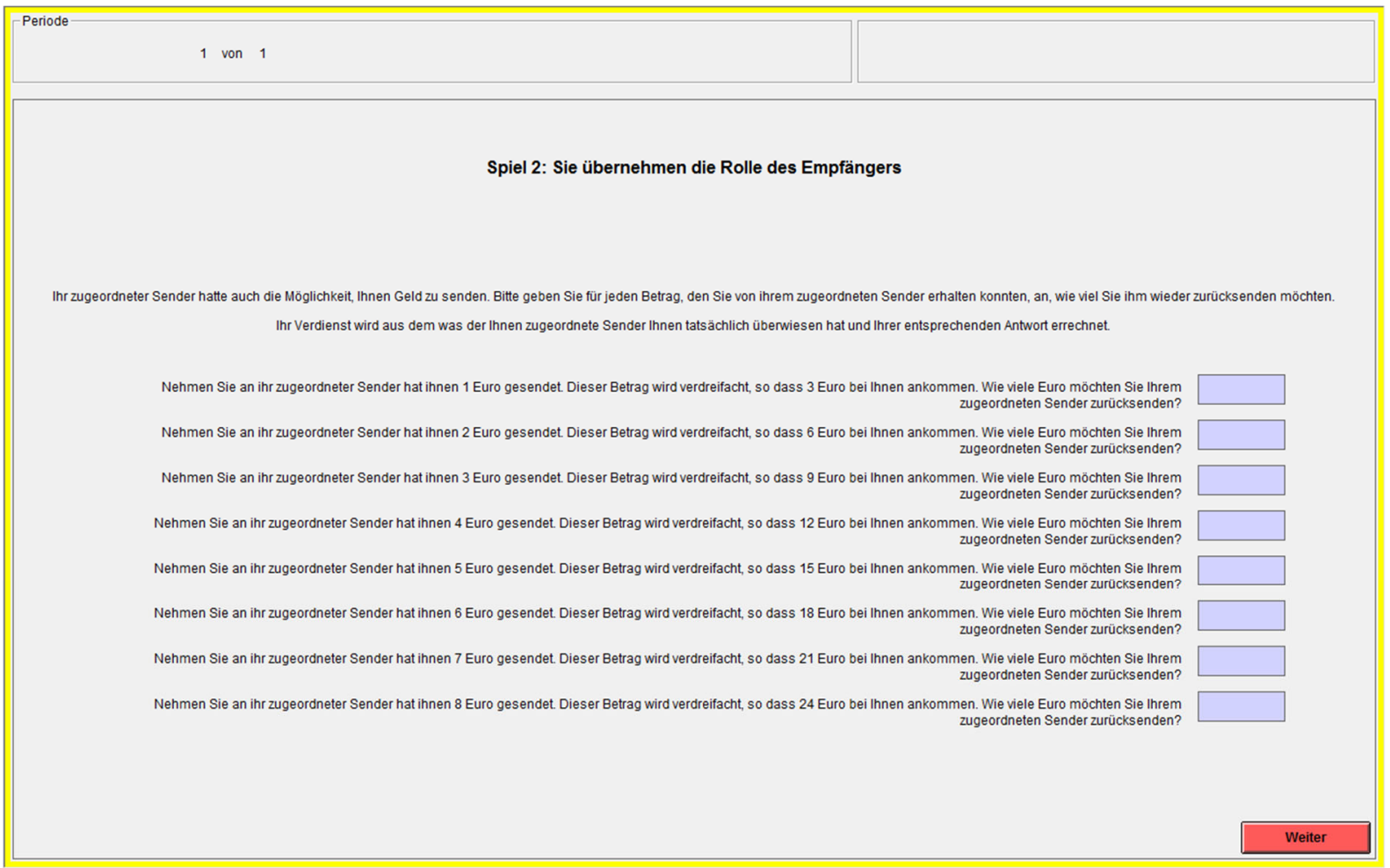

Game 2: You are the receiver. The participant with whom you are matched had the opportunity to send you money. Please, indicate for each amount that you may have received from the sender how much you would send back. Your payoff is calculated based on the real amount the sender has sent to you and your corresponding decision.

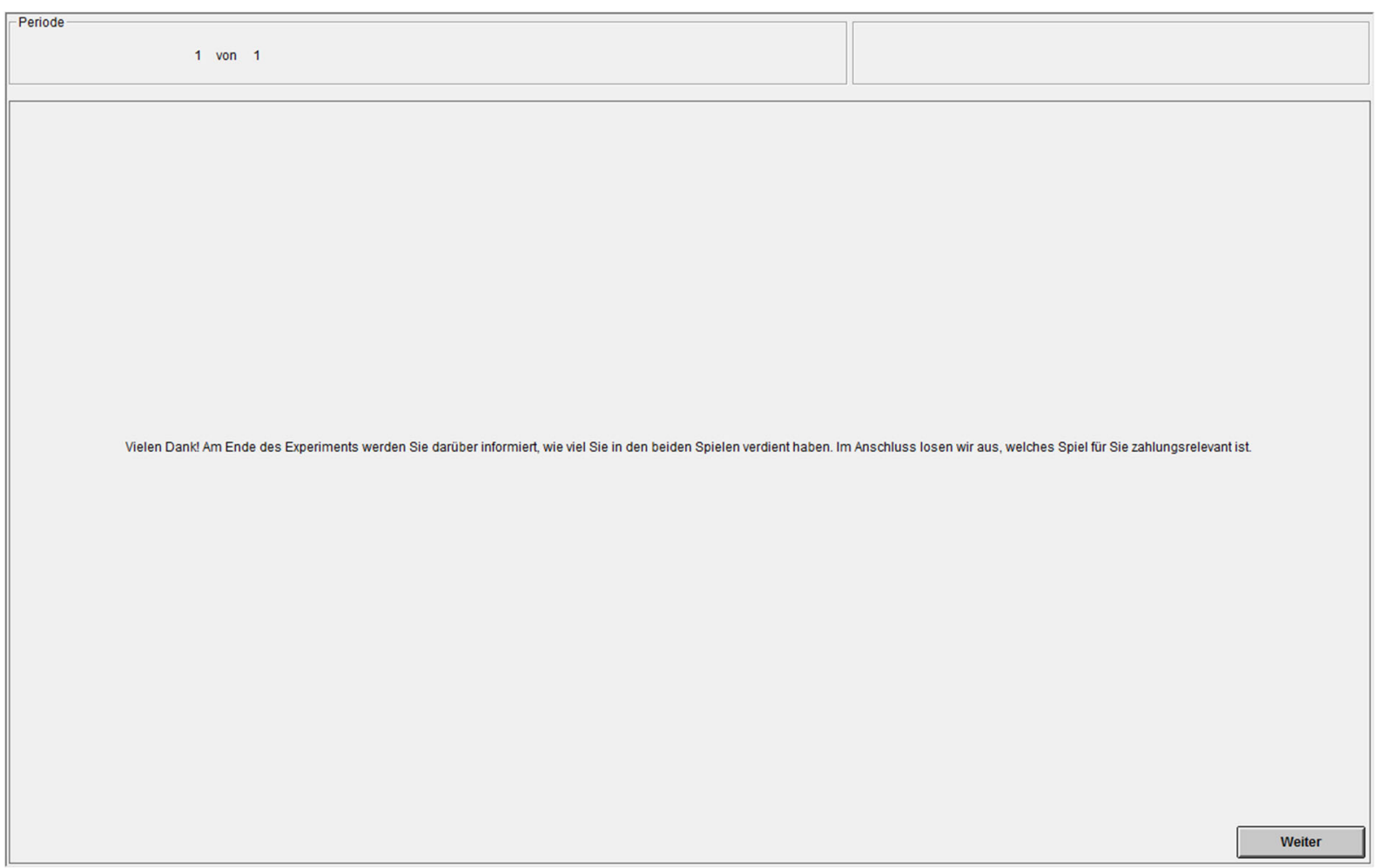

Thanks a lot! At the end of the experiment you will be informed how much money you earned in the two games. After this, we randomly select which game is payoff relevant. 

Fragen wahrheitsgemäß.

Now the last part of the experiment starts: A short questionnaire. Please, answer all questions truthfully. 


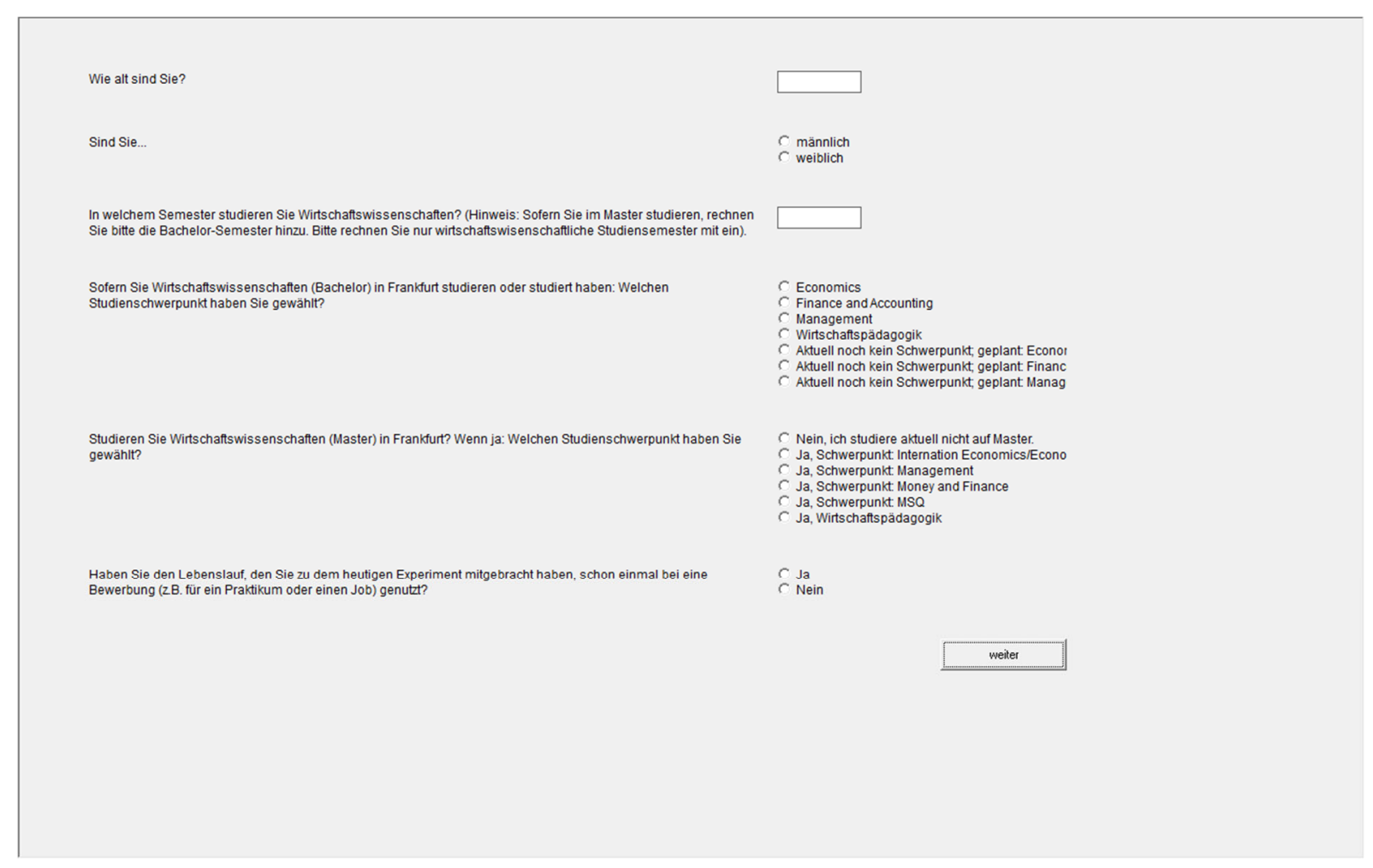

How old are you?

Are you male/female?

In which semester do you study economics? (Hint: If you are studying in the Master program, please also include your Bachelor-semesters. Please, count only semesters in economics.)

In case you are studying or you have studied economics (Bachelor) in Frankfurt, which specialization did you choose? Economics, Finance and Accounting, Management, business education, currently no specialization - planed Economics/Finance and Accounting/Management.

Are you studying economics (Master) in Frankfurt? If yes: Which specialization did you choose? No, I do not study in the Master program; Yes, specialization International Economics; Yes, specialization Management; Yes, specialization Money and Finance; Yes, specialization MSQ; Yes, specialization business education.

Have you ever used the résumé you brought today to the experiment for an application (e.g., for an internship or a regular job)? Yes/No 


\section{Online Appendix IV: Interview guide Wave 2020 (English translation)}

\section{Step 1: Interview invitation}

(a) Greetings, introduction of the research team.

(b) In 2013, we conducted a lab experiment at Goethe University Frankfurt in which we measured several personal characteristics of students. Today, we wish to study in which industries the former students with certain personal characteristics self-selected after finishing their studies. For the success of the study, it is important to know for as many subjects from the 2013 experiment as possible in which industries they are working today. We now contact all subjects from the experiment. You are one of them.

(c) We have two requests: Could we ask you a couple brief questions on your professional career? Are we allowed to link your answers with the data from the lab experiment from 2013 ? (d) For us, it is of utmost importance to reach as many of the former subjects as possible. Therefore, I contact you personally. We have a significant research budget. Since the response rate is so critical for us, we offer you 40 Euros for your participation in a five-minute interview. Also, we would make the results of our study available to you (in case you are interested).

(e) Privacy concerns: This is a critical topic for us, universities are taking this very seriously. We have a plan to protect your privacy that was recently accepted by an ethics committee. We can send you this plan if you want. An important part of this plan is that it will not be me who conducts the interview, but another interviewer who is not part of the team of authors.

(f) Neither your name, nor the name of any company will appear in our research dataset. The interviewer will record your answers, but he/she will anonymize all names through IDs and industry codes.

(g) Are you willing to participate in our interview? The interview can take place now or in one of the next days, according to your preferences. If you want to participate, please explicitly state that we can ask you a couple of brief questions on your professional career and that we are allowed to link your answers with the data from the lab experiment from 2013.

\section{Step 2: Interview}

(h) Greetings

(i) Professor XY told me that you are willing to participate in our interview. Many thanks for this. You will receive 40 Euros for your participation.

(j) All your answers will be anonymized by myself after the interview. I will also replace your name by an ID, and the names of companies by industry codes. 
(k) A few short questions first: How old are you? Which languages do you speak? Are you male/female? Did you volunteer before or during your studies (e.g., in a sports club or in the church)? If yes, provide more details on activity, organization, etc.

(l) We now would like to know more about your career: Could you briefly describe to me in which companies you worked (as an intern or working student)? When exactly did you study? Which company was your first, second, etc. employer after graduation? In which division of the company did you work? If you do not want to mention names of companies, you can also indicate the industry.

(m) Alternatively, if you do not want to describe your career in detail: A number of participants in this study offered us to collect the data about their career from their "LinkedIn" or "Xing" profile, instead of describing their career in detail. Would you prefer this option? If yes: Would you like to add anything that is not in your profile yet? Recall: According to our privacy plan we immediately anonymize the data.

(n) A couple of final brief questions: After graduation, how many applications did you write in total? To consulting firms? To auditing companies? To financial companies?

(o) [In case studies are not completed yet:] How many applications do you plan to submit? To consulting firms? To auditing companies? To financial companies?

(p) In which region did you grow up? 


\section{Online Appendix V: Cooperation and Professional Preferences: Experimental Instructions}

This lab experiment consists of two parts, Experiment 1 and Experiment 2. We begin with Experiment 1. Please, read the instructions carefully and make sure that you understand the rules of Experiment 1. From now on, please switch off your mobile phone and refrain from talking to other participants. If you have any questions, please raise your hand and we will come to your seat.

After Experiment 1 you will participate in Experiment 2. Importantly, Experiment 1 and Experiment 2 are independent of each other. Your decisions in Experiment 1 do not affect Experiment 2.

In both experiments, you can earn money by collecting tokens. The amount earned will be paid in cash at the end of the experiment. The exchange rate is

$$
1 \text { token }=0,35 \text { Euros. }
$$

All decisions will remain anonymous. Other participants will not learn about your true identity. Additionally to the earned amount you get 23 Euros for your participation.

\section{Overview of Experiment 1}

All participants will be divided into groups of three people. No participant knows the identity of the other two group members. Each group member has to decide on the allocation of 20 tokens. You can put these 20 tokens into your private account or you can invest them fully or partially into a project. Each token you do not invest into the project, will automatically remain in your private account.

Each group member profits from the amounts invested into the project. Your income in Experiment 1 will be determined as follows:

20 - Number of tokens you invested into the project

$+0.6 \mathrm{x}$ number of tokens invested by all group members.

Example: If all three group members invest 10 tokens each, then all group members earn

$$
20-10+0,6 \times 30=28 \text { tokens. }
$$

\section{Control questions}

Before we explain the details of the experiment, there are some control questions. Please, answer all control questions. They will help you to gain an understanding of the calculation of your income, which varies with your decision about how you distribute your 20 tokens.

1. Each group member has 20 tokens. None of the three group members contributes anything to the project.

What will your total income be?

What will the total income of 
the other two group members be?

2. Each group member has 20 tokens. You invest 20 points in the project. Each of the other two group members also contributes 20 tokens.

What will your total income be?

What will the total income of the other two group members be?

3. Each group member has 20 tokens. The other two group members contribute a total of 20 tokens.

a) What will your total income be, if you - in addition to the 20 tokens - invest 0 points into the project?

Your income:

b) What will your total income be, if you - in addition to the 20 tokens - invest 8 points into the project?

Your income:

c) What will your total income be, if you - in addition to the 20 tokens - invest 15 points into the project?

Your income:

4. Each group member has 20 tokens. Assume that you invest 8 tokens into the project.

a) What will your income be, if the other group members - in addition to your 8 tokens contribute in total 7 tokens into the project?

Your income:

b) What will your income be, if the other group members - in addition to your 8 tokens contribute in total 12 tokens into the project?

Your income:

c) What will your income be, if the other group members - in addition to your 8 tokens contribute in total 22 tokens into the project?

Your income: 


\section{Details for Experiment 1}

The experiment includes the decision situation just described to you. The experiment will only be conducted once. As you know, you will have 20 tokens at your disposal. You can keep them for yourself or you can invest them into the project. Each subject has to make two types of decisions in this experiment, which we will refer to as the "unconditional contribution" and "conditional contribution".

First, you indicate your unconditional contribution on the following screen:

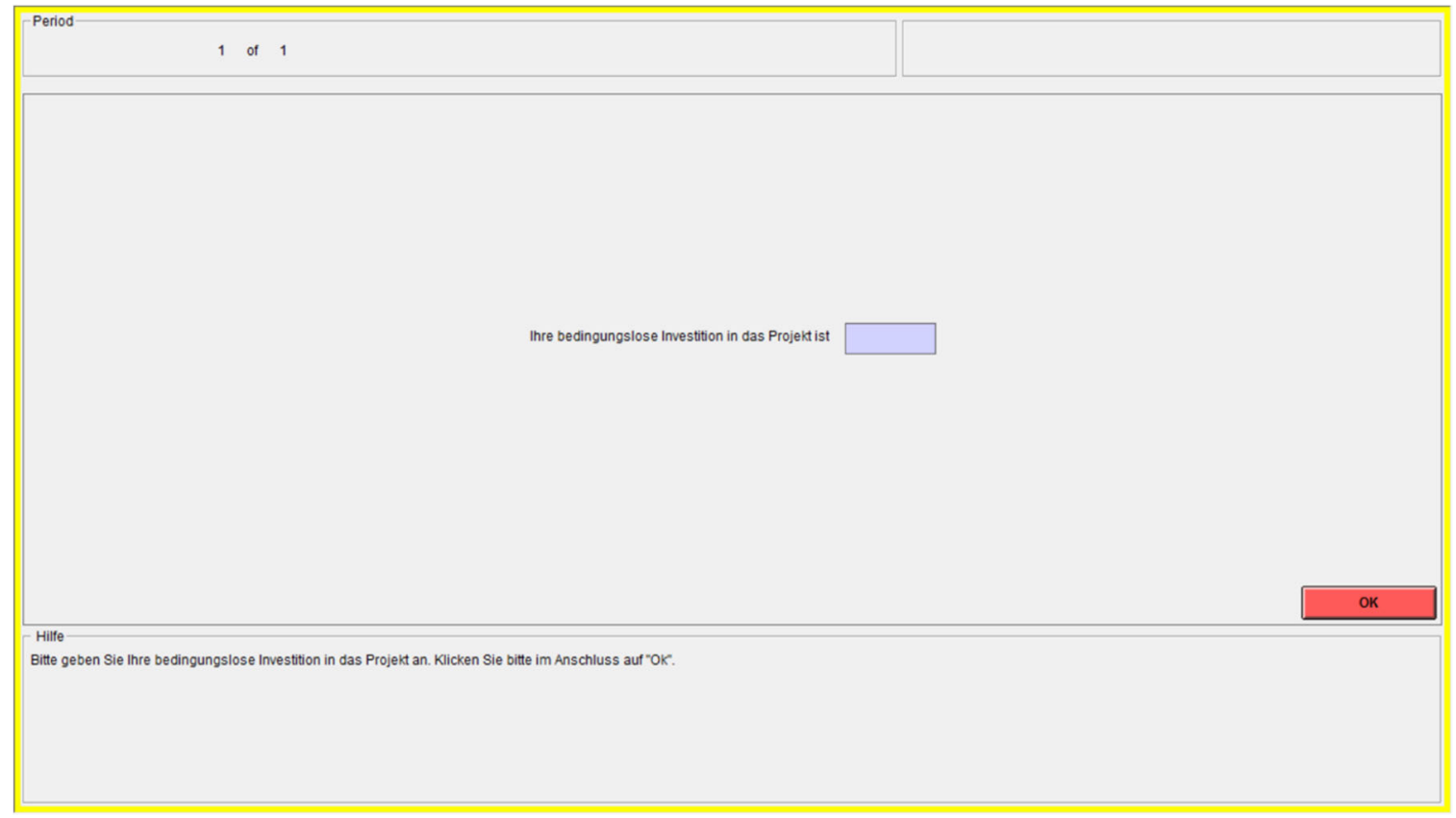

After you made your decision, please click "OK". Then you indicate your conditional contribution for each possible average contribution of the other group members (rounded to the next integer) on the following screen:

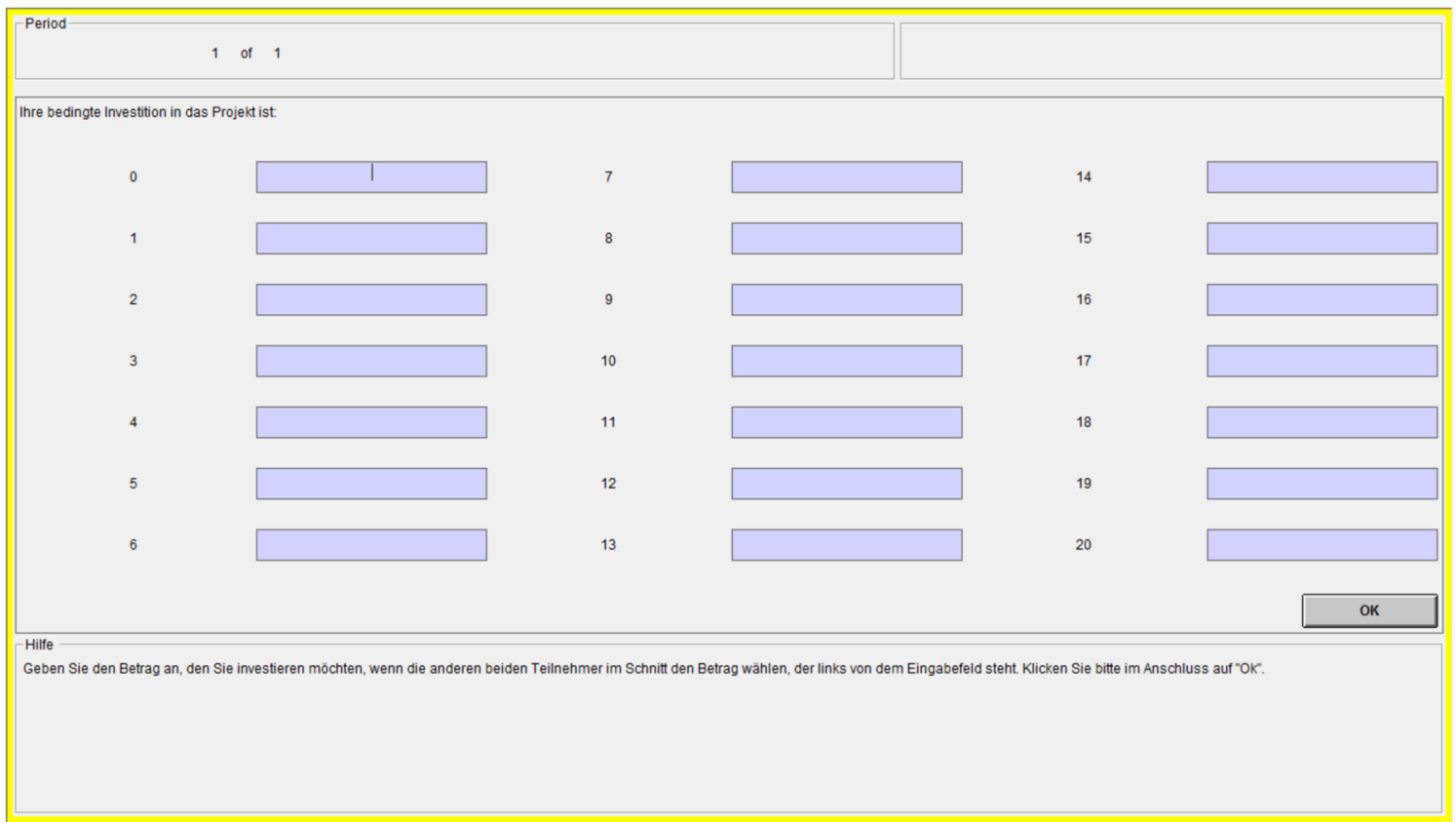


As you can see, you can make your contribution dependent on the average contribution of the other group members. The numbers next to each input box shows the possible (rounded) average contributions of the other group members. You have to indicate for each average contribution, how much you would like to invest into the project. You can choose any integer between 0 and 20. Once you have made an entry in each input box, please click "OK".

After all participants of the experiment have made all decisions, a random mechanism will select a group member from every group. Only the conditional contribution will be the payoff-relevant decision for the randomly determined subject. Only the unconditional contribution will be the payoff-relevant decision for the other two group members not selected by the random mechanism. You do not know which of your decisions will be realized. You will therefore have to think carefully about both the conditional and the unconditional contribution. Two examples should make this clear.

Example 1: Assume that the random mechanism selects you. This implies that your relevant decision will be your conditional contribution. The unconditional contribution is the relevant decision for the other two group members. Assume they made unconditional contributions of 1 and 3 tokens. The average contribution is therefore 2 tokens. Your conditional contribution for 2 tokens is then relevant for your payment. If this decision was 1 tokens, the total investments are $1+3+1=5$ tokens, and your income is

$$
20-1+0,6 \times 5=22 \text { tokens. }
$$

If your conditional contribution for 2 tokens was 19 tokens instead, your income is

$$
20-19+0,6 \times 23=14,8 \text { tokens. }
$$

Example 2: Assume that the random mechanism did not select you. Thus, your unconditional contribution is taken as the payoff-relevant decision. Assume your unconditional contribution is 16 tokens, and those of the other group member, who was not selected, is 20 tokens. The average contribution is therefore 18 tokens. So the conditional contribution of the selected group member for 18 tokens is payoff-relevant. If the decision was 1 token, your income is

$$
20-16+0,6 \times 37=26,2 \text { tokens. }
$$

If instead the selected group member decided to contribute 19 for the case of an average contribution of 18 tokens, your income is

$$
20-16+0,6 \times 55=37 \text { tokens. }
$$

